\title{
Michael Stolz
}

\section{Vivus est sermo tuus. \\ Religion und Wissen in der Prager Hofkultur des 14. Jahrhunderts}

Bibliografische Information der Deutschen Nationalbibliothek

Die Deutsche Nationalbibliothek verzeichnet diese Publikation in der Deutschen Nationalbibliografie; detaillierte bibliografische Daten sind im Internet über http://dnb.d-nb.de abrufbar.

\section{(C) Akademie Verlag GmbH, Berlin 2013}

Ein Wissenschaftsverlag der Oldenbourg Gruppe

\section{www.akademie-verlag.de}

Das Werk einschließlich aller Abbildungen ist urheberrechtlich geschützt. Jede Verwertung außerhalb der Grenzen des Urheberrechtsgesetzes ist ohne Zustimmung des Verlages unzulässig und strafbar. Das gilt insbesondere für Vervielfältigungen, Übersetzungen, Mikroverfilmungen und die Einspeicherung und Bearbeitung in elektronischen Systemen.

Umschlagentwurf: hauser lacour

Druck \& Bindung: Beltz Bad Langensalza GmbH, Bad Langensalza

Dieses Papier ist alterungsbeständig nach DIN/ISO 9706.

ISBN 978-3-05-006397-3

eISBN $\quad 978-3-05-006399-7$
Die Spannung von Religion und Wissen ist seit dem frühen Christentum ein Dauerthema in der europäischen Geistesgeschichte. ${ }^{1}$ Suchten die Kirchenväter die Interpretation der Bibel mit dem Instrumentarium der heidnischen Wissenschaften $\mathrm{zu}$ rechtfertigen ${ }^{2}$ so

1 Das Verhältnis wird bis in die jüngste Zeit, nicht zuletzt im Hinblick auf den Dialog zwischen den Religionen, diskutiert, wie u. a die kontroverse Reaktion auf die Regensburger Rede von Papst Benedikt XVI. (Joseph Ratzinger) über ,Glaube und Vernunft' im September 2006 zeigt. Vgl. stellvertretend Benedikt XVI., Glaube und Vernunft. Die Regensburger Vorlesung. Vollständige Ausgabe. Kommentiert von Gesine Schwan, Adel Theodor Khoury, Karl Lehmann. Freiburg i. Br. / Basel / Wien 2006; Benedikt XVI. u. a., Dio salvi la ragione. Rom 2007 (dt. Ubers.: Gott, rette die Vernunft! Die Regensburger Vorlesung des Papstes in der philosophischen Diskussion. Augsburg 2008); Jean Bollack / Christian Jambet / Abdelwahab Meddeb, La conférence de Ratisbonne. Enjeux et controverses. Paris 2007; Christoph Dohmen (Hrsg.), Die ,Regensburger Vorlesung' Papst Benedikts XVI. im Dialog der Wissenschaften. Regensburg 2007; James V. Schall, The Regensburg Lecture. South Bend Indiana 2007; Knut Wenzel (Hrsg.), Die Religionen und die Vernunft. Die Debatte um die Regensburger Vorlesung des Papstes. Freiburg i. Br. 2007; Haider Ali Zafar (Hrsg.), Glaube und Vernunft aus islamischer Perspektive. Antwort auf die Regensburger Vorlesung vom Papst Benedikt XVI. Frankfurt a. M. 2007; Erwin Dirscherl/ Christoph Dohmen (Hrsg.), Glaube und Vernunft. Spannungsreiche Grundlage europäischer Geistesgeschichte. (Forschungen zur europäischen Geistesgeschichte, Bd. 9.) Freiburg i. Br. 2008; Görge K. Hasselhoff/Michael Meyer-Blanck (Hrsg.), Religion und Rationalität. (Studien des Bonner Zentrums für Religion und Gesellschaft, Bd. 4.) Würzburg 2008; Heinz Otto Luthe / Carsten-Michael Walbiner (Hrsg.), Anstoß und Aufbruch. Zur Rezeption der Regensburger Rede Papst Benedikts XVI. bei Christen und Muslimen. (Aufbrüche. Interkulturelle Perspektiven auf Geschichte, Politik und Religion.) Bochum 2008. Zur Thematik allgemein u. a. Georges Cottier, Les Chemins de la raison. Questions d'épistémologie théologique et philosophique. (Collection Sagesse et cultures.) Saint-Maur 1997; Mariano Delgado / Guido Vergauwen (Hrsg.), Glaube und Vernunft. Theologie und Philosophie. Aspekte ihrer Wechselwirkung in Geschichte und Gegenwart. (Ökumenische Beih. zur Freiburger Zeitschrift für Philosophie und Theologie, Bd. 44.) Freiburg, Schweiz 2003; Alain de Libera, Raison et foi. Archéologie d'une crise d'Albert le Grand à Jean-Paul II. (L'ordre philosophique.) Paris 2003.

2 Vgl. stellvertretend Kurt Flasch, Das philosophische Denken im Mittelalter. Von Augustin zu Machiavelli. Stuttgart ${ }^{2} 2000,152-155$; Michael Stolz, Artes-liberales-Zyklen. Formationen des 
arbeiteten Frühscholastiker wie Anselm von Canterbury an einer rationalen Begründung des überlieferten Glaubens (sola ratione), ${ }^{3}$ ehe Vertreter des Nominalismus wie Wilhelm von Ockham dem Glauben als willensbestimmtem Bekenntnis „einen rational nicht anfechtbaren Sonderstatus sicher[te]n" ${ }^{4}{ }^{4}$ Im vorliegenden Beitrag soll das Verhältnis von Religion und Wissen in einem spezifischen historischen Kontext untersucht werden jenem der von Karl IV. geprägten Prager Hofkultur des 14. Jahrhunderts. ${ }^{5} \mathrm{Zu}$ diesem

Wissens im Mittelalter. (Bibliotheca Germanica, Bd. 47.1-2.) Tübingen / Basel 2004, Bd. 1, 10-16, mit weiterer Literatur.

3 Vgl. stellvertretend Michel Corbin, Prière \& raison de la foi. Introduction à l'œuvre de Saint Anselme de Cantorbéry. (L'œuvre d'Anselme de Cantorbéry. Introduction générale.) Paris 1992; Stephan Ernst, Ethische Vernunft und christlicher Glaube. Der Prozess ihrer wechselseitigen Freisetzung in der Zeit von Anselm von Canterbury bis Wilhelm von Auxerre. (Beiträge zur Geschichte setzung in der Zeit von Anselm von Canterbury bis Wilhelm von Auxerre. (Beiträge zur Geschichte
der Philosophie und Theologie des Mittelalters, N. F., Bd. 46.) Münster 1996; Flasch, Philosophisches Denken (wie Anm. 2), 202-207; Rolf Schönberger, Anselm von Canterbury (1033-1109) und Peter Abaelard (ca. 1079-1142), in: Otfried Höffe (Hrsg.), Klassiker der Philosophie, Bd. 1: Von den Vorsokratikern bis David Hume. München ${ }^{4} 2008$, 176-194, bes. 177f. Stephan Ernst / Thomas Franz (Hrsg.), Sola ratione. Anselm von Canterbury (1033-1109) und die rationale Rekonstruktion des Glaubens. Würzburg 2009; Stephan Ernst, Anselm von Canterbury. (Zugänge zum Denken des Mittelalters, Bd. 6.) Münster 2011, bes. 23-29.

4 Flasch, Philosophisches Denken (wie Anm. 2), 501. Vgl. zu Wilhelm von Ockham auch stellvertretend Sigrid Müller, Handeln in einer kontingenten Welt. Zu Begriff und Bedeutung der rechten Vernunft (recta ratio) bei Wilhelm von Ockham. (Tübinger Studien zur Theologie und Philosophie, Bd. 18.) Tübingen 2000; Volker Leppin, Wilhelm von Ockham. Gelehrter, Streiter, Bettelmönch. Darmstadt 2003, bes. 47-54; Ruedi Imbach, Wilhelm von Ockham (um 1285 - um 1349), in: Otfried Höffe (Hrsg.), Klassiker der Philosophie, Bd. 1: Von den Vorsokratikern bis David Hume München ${ }^{4} 2008,211-224$, bes. $220 \mathrm{f}$

5 Vgl. Winfried Baumann, Die Literatur des Mittelalters in Böhmen. Deutsch-lateinisch-tschechische Literatur vom 10. bis zum 15. Jahrhundert. (Veröffentlichungen des Collegium Carolinum, Bd. 37.) München / Wien 1978, bes. 189-211; Hans Patze (Hrsg.), Kaiser Karl IV. 1316-1378. Forschungen über Kaiser und Reich. (Sonderabdruck der Aufsätze aus: Blätter für deutsche Landesgeschichte 114 , München 1978; Ders., (Hrsg.), Kaiser Karl IV. Staatsmann und Mäzen. München 1978; Ders. (Hrsg.), Karl IV. und sein Kreis. (Lebensbilder zur Geschichte der böhmischen Länder, Bd. 3.) München / Wien 1978; Jiř́ Spěváček, Karl IV. Sein Leben und seine staatsmännische Leistung. Wien / Köln / Graz 1978; Karel Stejskal / Karel Neubert, Karl IV. und die Kultur und Kunst seine Zeit. Hanau 1978; František Kavka, Am Hofe Karls IV. Stuttgart ${ }^{2} 1990$; Bernd-Ulrich Hergemöller, Cogor adversum te. Drei Studien zum literarisch-theologischen Profil Karls IV. und seiner Kanzlei. Kaiser von Gottes Gnaden. Kuns Kaiser von Gos (Gnaden. Kunst und Repran München / Berlin 2006, zu diesem anlässlich von Ausstellungen in New York und Prag 2006 erschienen Band, der auch in tschechischer und in anderer Form in englischer Sprache erschienen ist, $\mathrm{Ka}$ Wenzel, ,Karl IV. - Kaiser von Gottes Gnaden`. Neue Studien zur Hofkunst der Luxemburger, in Bohemia 47, 2006/2007, 27-43; Eva Schlotheuber, Der Ausbau Prags zur Residenzstadt und die Herrschaftskonzeption Karls IV., in: Markéta Jarošová / Jiři Kuthan / Stefan Scholz (Hrsg.), Prag und die großen Kulturzentren Europas in der Zeit der Luxemburger (1310-1437). Internationale Konferenz aus Anlass des 660. Jubiläums der Gründung der Karlsuniversität Prag, 31. März-5. April 2008. I
Zweck soll ein exemplarisches Textzeugnis vorgestellt werden, in dem das zu dieser Zeit letztlich nicht vereinbare Gegeneinander religiöser und wissensgeleiteter Zuschreibungen in einen diskursiven Widerstreit gerät. Der Begriff des ,Widerstreits“ ist dabei an den von Jean-François Lyotard in die Postmoderne-Diskussion eingebrachten Terminus ,Le différend“ angelehnt, dẹ auf das inkommensurable Gegeneinander von Sprachspielen (im Sinne Wittgensteins) verweist. ${ }^{6}$

Vielleicht kann auf diese Weise auch ein bescheidener Beitrag zur Neubestimmung des sogenannten ,Prager Frühhumanismus' geleistet werden. Der von Konrad Burdach im frühen 20. Jahrhundert geprägte, an die Entstehung einer neuhochdeutschen Schriftsprache gebundene Begriff konnte sich bekanntlich nicht durchsetzen. ${ }^{8}$ Er wurde jedoch bislang nicht durch ein überzeugendes Beschreibungsverfahren ersetzt, das die in der

Prague and Great Cultural Centres of Europe in the Luxembourgeois Era (1310-1437). International Conference on the occasion of the $660^{\text {th }}$ anniversary of the foundation of Charles University in Prague, $31^{\text {st }}$ March-5 $5^{\text {th }}$ April 2008. Praha 2008, 601-621; Jiř Fajt / Andrea Langer (Hrsg.), Kunst als Herrschaftsinstrument. Böhmen und das Heilige Römische Reich unter den Luxemburgern im europäischen Kontext. München 2009; Richard Němec, Kulturlandschaft und Staatsidee'. Architektur und Herrschaftskonzeption Karls IV, in: Eva Schlotheuber/Hubertus Seibert (Hrsg), Böhmen und das Deutsche Reich. Ideen- und Kulturtransfer im Vergleich (13.-16. Jahrhundert). (Veröffentlichungen des Collegium Carolinum, Bd. 116.) München 2009, 63-102.

6 Vgl. Jean-François Lyotard, Le différend. Paris 1983. Dazu Wolfgang Welsch / Christine Pries (Hrsg.), Ästhetik im Widerstreit. Interventionen zum Werk von Jean-François Lyotard. Weinheim 1991; Dietmar Köveker (Hrsg.), Im Widerstreit der Diskurse. Jean-François Lyotard und die Idee der Verständigung im Zeitalter globaler Kommunikation. (Schriftenreihe des Frankreich-Zentrums der Technischen Universität Berlin, Bd. 8.) Berlin 2004

7 Vgl. Konrad Burdach (Hrsg.), Vom Mittelalter zur Reformation. Forschungen zur Geschichte der deutschen Bildung, Bd. 2-11. Berlin 1912-1937; Joseph Klapper, Johann von Neumarkt. Bischof und Hofkanzler - religiöse Frührenaissance in Böhmen zur Zeit Kaiser Karls IV. (Erfurter theologische Studien, Bd. 17.) Leipzig 1964, bes. 14-18; Eduard Winter, Frühhumanismus. Seine Entwicklung in Böhmen und deren europäische Bedeutung für die Kirchenreformbestrebungen im 14. Jahrhundert. (Beiträge zur Geschichte des religiösen und wissenschaftlichen Denkens, Bd. 3.) Berlin 1964.

8 Vgl. zur Kritik zuletzt Siegfried Grosse, Zur Diskussion über die Entstehung der neuhochdeutschen Schriftssprache, in: Seibt, Kaiser Karl IV. Staatsmann und Mäzen (wie Anm. 5), 260-264; Peter Wiesinger, Das Verhältnis des Prager Kreises um Karl IV. zur neuhochdeutschen Schriftssprache, in: Patze, Kaiser Karl IV. (wie Anm. 5), 847-863; John M. Clifton-Everest, Johann von Neumarkt und Cola di Rienzo, in: Bohemia 28, 1987, 25-44, bes. 25-28; Benedikt Konrad Vollmann, Prager Frühhumanismus?, in: Joachim Heinzle / L. Peter Johnson / Gisela Vollmann-Profe (Hrsg.), Literatur im Bd. 13.) Berlin 1994, 58-66. Der Ansatz eines, Prager Frühhumanismus' wird, wenn auch mit Modifikationen, in der tschechischen Forschung weitergefüht; vgl. stellvertretend František Michálek Bartoš, Dantova ,Monarchie', Cola di Rienzo, Petrarka a počátky reformace a humanismu u nás, in: Věstník Královské české společnosti nauk. Tř́da filosoficko-historicko-filologická, 1951, 1-23, sowie zuletzt Jana Nechutová, Die lateinische Literatur des Mittelalters in Böhmen. (Bausteine zur slavischen Philologie und Kulturgeschichte, N.F. Reihe A: Slavistische Forschungen, Bd. 59.)

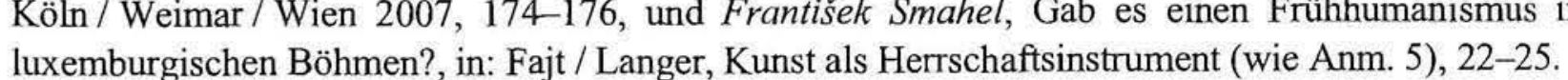


Prager Kultur des 14. Jahrhunderts unverkennbar vorhandenen Reformbestrebungen angemessen zu erfassen vermag. Die im intellektuellen Leben Prags festzustellenden Bewegungen sind nicht eindimensional festlegbar - etwa im Hinblick auf die Entstehung einer neuhochdeutschen Schriftsprache. Vielmehr sind sie von konkurrierenden und interagierenden Sprachen sowie den damit verbundenen Artikulationsformen und kulturellen Vorverständnissen geprägt: von der übergreifenden Gelehrtensprache Latein ebenso wie von den Volkssprachen Deutsch, Tschechisch, Französisch, Italienisch; eine wichtige Rolle spielen zudem die jüdische Kultur sowie das Jiddische und Hebräische.

Die aus dieser Situation resultierende Vielstimmigkeit artikuliert sich in Texten, die allein - neben Bezeichnungspraktiken, wie sie in bildlichen und architektonischen Zeugnissen hervortreten - der historischen und geistesgeschichtlichen Analyse zugänglich sind. Der befrachtete Begriff ,Geistesgeschichte“ wird in diesem Zusammenhang ganz bewusst verwendet, denn er scheint mit den aus der angelsächsischen, Intellectual History“ hervorgegangenen Anregungen geeignet zu sein, die Prager Verhältnisse des 14. Jahrhunderts neu zu beschreiben.

Vertreter der ,Intellectual History“ wie Quentin Skinner und John Pocock haben in ihren Arbeiten gezeigt, dass geistesgeschichtliche Forschung der Analyse kommunikativer Situationen und der in ihrem Rahmen vollzogenen Sprachhandlungen bedarf. ${ }^{10}$

9 Die kulturellen Interferenzen bedürften einer gründlichen Aufarbeitung. Als Ausgangspunkte aus literarhistorischer Perspektive könnten Texte von Johann von Neumarkt, Heinrich von Mügeln, Johannes von Tepl (,Ackermann'), der alttschechische, Tkadleček', Texte von Milíč von Kremsier und Konra Waldher, Guilames de Macht, Jugement dou Roy de Behing ', Petracis litearisches Werk sowie Gedichte wie ,Almekhtige Got eynig un eyn" von dem Prager Rabbiner Avigdor Kara-ben-Isaak (ein Text, der sich gegen die christliche Inkarnationslehre richtet) dienen. Vgl. vorab Baumann, Literatur des Mittelalters in Böhmen (wie Anm. 5); Seibt, Karl IV. Kaiser (wie Anm. 5), 367-376; Nechutová, Lateinische Literatur in Böhmen (wie Anm. 8), bes. 169-183, 237269; Martin Schubert, Inszenierung und Repräsentation von Herrschaft. Karl IV. in der Literatur, in: Ulrike Hohensee / Mathias Lawo/ Michael Lindner et al. (Hrsg.), Die Goldene Bulle. Politik Wahrnehmung - Rezeption. (Berlin-Brandenburgische Akademie der Wissenschaften. Berichte und Abhandlungen, Sonderband 12.) Berlin 2009, Bd. 1, 493-516; sowie die anregenden Studien zum jüdischen Kontext von Albrecht Hausmann, Der, Ackermann' des Johannes von Tepl und die Prager Juden um 1400, in: Beiträge zur Geschichte der deutschen Sprache und Literatur 125, 2003, $292-$ 323, und Ders., Böhmen um 1400 als kultureller Interferenzraum. Überlegungen zum ,Ackermann aus Böhmen` des Johannes von Tepl, in: Ralf G. Päsler / Dietrich Schmidtke (Hrsg.), Deutschsprachige Literatur des Mittelalters im östlichen Europa. Forschungsstand und Forschungsperspektiven. Heidelberg 2006, 475-481, ferner Vivian B. Mann, Die Juden und der Herrscherhof, in: Fajt, Karl IV. Kaiser von Gottes Gnaden (wie Anm. 5), 277-289.

10 Vgl. im Zusammenhang des politischen Denkens im 15. und 16. Jahrhundert Quentin Skinner, The Foundations of Modern Political Thought, Bd. 1: The Renaissance, Bd. 2: The Age of Reformation. Cambridge 1978; dazu Annabel Brett / James Tully / Holly Hamilton-Bleakley (Hrsg.), Rethinking the Foundations of Modern Political Thought. Cambridge 2006; ferner im Zusammenhang der frühnouzeitlichen Retorik im Werk von Thomas Hobbes Quentin Skinner, Reason (19) Philosophy of Hobbes. Cambridge 1996. Unter den Arbeiten Pococks sei verwiesen auf die Aufsatzbände $\int[o h n]$ G[reville] A[gard] Pocock, Politics, Language and Time.
Anregungen der ,Intellectual History ' wurden implizit und explizit von Historikern wie Dominick LaCapra, David Harlan und Gabrielle M. Spiegel aufgegriffen und dabei kritisch weiterentwickelt. ${ }^{11}$ Im Kern dieser Arbeiten zeigt sich der Ansatz, dass historische Wirklichkeit in der Regel nur über Sprache fassbar wird. Wiederholt finden sich Bezugnahmen auf Hayden Whites Kritik an einer vermeintlich faktenorientierten Geschichtsschreibung ${ }^{12}$ und Verweise auf Jacques Derridas Diktum „Ein Text-Äußeres gibt es nicht" (,il n'y a pas de hors texte" $).{ }^{13}$ Der Text, auf den sich das zentrale Erkenntnisinteresse richtet, wird als ,situative[r] Gebrauch von Sprache“ verstanden. ${ }^{14}$ Als komplex erweist sich dabei die Bestimmung des Textes als solcher zu dessen Kontexten, da diese in der Regel ihrerseits nur sprachlich, also wiederum als Texte,

Essays on Political Thought and History. London 1972, darin besonders die Einleitung Ders., Languages and their Implications. The Transformation of the Study of Political Thought, 3-41 (dt.: Sprachen und ihre Implikationen. Die Wende in der Erforschung des politischen Denkens, in: Martin Mulsow/Andreas Mahler [Hrsg.], Die Cambridge School der politischen Ideengeschichte. Frankfurt a. M. 2010, 88-126), und John] G[reville] A[gard] Pocock, Political Thought and History. Essays on Theory and Method. Cambridge 2009, sowie auf die umfangThought and History. Essays on Theory and Method. Cambridge 2009, sowie auf die umfang-
reiche Studie über die politische Sprache des Republikanismus vom 15, Jahrhundert bis zur Gründungszeit der Vereinigten Staaten: Ders., The Machiavellian Moment. Florentine Political Thought and the Atlantic Republican Tradition. Princeton 1975.

11 Vgl. Dominick LaCapra, Rethinking Intellectual History and Reading Texts, in: Ders. / Steven L. Kaplan (Hrsg.), Modern European Intellectual History. Reappraisals and New Perspectives. Ithaca / London 1982, 47-85 (dt: Geistesgeschichte und Interpretation, in: Ders. / Steven L. Kaplan (Hrsg.), Geschichte denken. Neubestimmungen und Perspektiven moderner europäischer Geistesgeschichte. Frankfurt a. M. 1988, 45-86); David Harlan, Intellectual History and the Return of Literature, in: American Historical Review 94, 1989, 581-609 (dt.: Der Stand der Geistesgeschichte und die Wiederkehr der Literatur, in: Martin Mulsow / Andreas Mahler [Hrsg.], Die Cambridge School der politischen Ideengeschichte. Frankfurt a. M. 2010, 155-20); Gabrielle M. Spiegel, History, Historicism, and the Social Logic of the Text in the Middle Ages, in: Speculum 65, 1990, 59-86 (dt.: Geschichte, Historizität und die soziale Logik von mittelalterSpeculum 65, 1990, 59-86 (dt.: Geschichte, Historizität und die soziale Logik von mittelalter-
lichen Texten, in: Christoph Conrad / Martina Kessel [Hrsg.], Geschichte schreiben in der Postlichen Texten, in: Christoph Conrad / Martina Kessel [Hrsg.], Geschicht
moderne. Beiträge zur aktuellen Diskussion. Stuttgart 1994, 161-202)

12 Vgl. LaCapra, Geistesgeschichte und Interpretation (wie Anm. 11), 82, Anm. 1, und Spiegel, Geschichte, Historizität (wie Anm. 11), 198, Anm. 16, mit Verweisen auf Hayden White, Metahistory. The Historical Imagination in Nineteenth-Century Europe. Baltimore 1973 (dt:: Metahistory. Die historische Einbildungskraft im 19. Jahrhundert in Europa. Frankfurt a. M. 1991); Ders., Tropics of discourse. Essays in Cultural Criticism. Baltimore 1985 (dt.: Auch Klio dichtet oder die Fiktion des Faktischen. Studien zur Tropologie des historischen Diskurses. Einführung von Reinhart Koselleck. [Sprache und Geschichte, Bd. 10.] Stuttgart 1986); Ders., The Content of the Form. Narrative Discourse and Historical Representation. Baltimore/London 1987 (dt.: Die Bedeutung der Form. Erzählstrukturen in der Geschichtsschreibung. Frankfurt a. M. 1990).

13 Z. B. Spiegel, Geschichte, Historizität (wie Anm. 11), 167, zu Jacques Derrida, De la grammatologie. Paris 1967, 274 (dt.: Grammatologie. Frankfurt a. M. 1974).

14 Spiegel, Geschichte, Historizität (wie Anm. 11), 180, mit Verweis auf LaCapra, Geistesgeschichte und Interpretation (wie Anm. 11), 47f. 
zugänglich sind. LaCapra versucht im Rahmen dieses Begriffs von ,Textualität", ${ }^{15}$ unterschiedliche Kategorien des Kontextuellen zu bestimmen, so die in der ,Intellectual History' stark gemachte Intention des Autors (als hermeneutische Größe bekanntlich ein Problem für sich) ${ }^{16}$ ferner die Lebensumstände des Autors und das Korpus der unter seinem Namen überlieferten Schriften (zwei in der poststrukturalistischen Autordebatte intensiv diskutierte Größen) ${ }^{17}$ schließlich gesellschaftliche und kulturelle Verhältnisse sowie die in ihrem Zusammenhang offenbar werdenden Diskursformen. ${ }^{18}$

Im Hinblick auf die intellektuelle Situation Prags im 14. Jahrhundert ist interessant, dass dieses von der ,Intellectual History ' geprägte Konzept der ,Textualität‘ Texte auch als „Ereignisse der Sprachgeschichte“ begreift, ${ }^{19}$ dass es Texte in „,soziale Räume“ ${ }^{20}$ in „politische und soziale Netzwerke" einordnet, ${ }^{21}$ unter anderem auch in Gesellschaften mit „differenzierte[r] Mehrsprachigkeit ${ }^{\text {‘22 }}$ sowie in die damit verbundenen „Diskursräume(n) und Transferprozesse(n) ${ }^{\star 23}$

In diesem Horizont soll nun ein Brief betrachtet werden, in dem sich ein Bischof, sehr wahrscheinlich Johann von Neumarkt, an den Prager Kaiser Karl IV. wendet. ${ }^{24}$ Es ist hier also eine Kommunikationssituation anzutreffen, die sich zwischen einem Kleriker und einem Laien, zwischen geistlichem Würdenträger und weltlichem Herrscher abspielt. Der Brief ist in einer Handschrift des früheren 15. Jahrhunderts überliefert, die neben dem ,Morale Somnium Pharaonis ' des Johannes von Limoges und der ,Ars

15 LaCapra, Geistesgeschichte und Interpretation (wie Anm. 11), 48.

16 Vgl. Fotis Jannidis / Gerhard Lauer / Matias Martinez et al. (Hrsg), Rückkehr des Autors. Zur Erneuerung eines umstrittenen Begriffs. (Studien und Texte zur Sozialgeschichte der Literatur, Bd. 71.) Tübingen 1999; darin bes. den Beitrag von Lutz Danneberg, Zum Autorkonstrukt und zu einem methodologischen Konzept der Autorintention, ebd., 77-105.

17 Vgl. Michel Foucault, Qu'est-ce qu'un auteur?, in: Bulletin de la Société française de Philosophie 63, 1969, Nr. 3, 73-104; erweiterter Nachdruck in: Ders., Dits et Écrits 1954-1988. Paris 2001, Bd. 1, 817-849 (dt: Ders., Was ist ein Autor?, in: Ders, Schriften zur Literatur. Frankfurt a. M. 1988, 7-31; erweiterter Nachdruck in: Ders., Schriften zur Literatur. Hrsg. von Daniel Defert / François Ewald. Frankfurt a. M. 2003, 234-270); dazu Fotis Jannidis/Gerhard Lauer/Matias Martinez et al., Rede über den Autor an die Gebildeten unter seinen Verächtern. Historische Modelle Martinez et al., Rede über den Autor an die Gebildeten unter seinen Verächtern. Historische Mode
und systematische Perspektiven, in: Dies., Rückkehr des Autors (wie Anm. 16), 3-35, hier 14f.

18 LaCapra, Geistesgeschichte und Interpretation (wie Anm. 11), 53-81.

19 LaCapra, Geistesgeschichte und Interpretation (wie Anm. 11), 78.

20 Spiegel, Geschichte, Historizität (wie Anm. 11), 181.

21 Spiegel, Geschichte, Historizität (wie Anm. 11), 190

22 Vgl. Willibald Steinmetz, Vierzig Jahre Begriffsgeschichte - ,The State of the Art', in: Heidrun Kämper / Ludwig M. Eichinger (Hrsg.), Sprache - Kognition - Kultur. Sprache zwischen mentaler Struktur und kultureller Prägung. Berlin / New York 2008, 174-197, hier 192.

23 Vgl. Günther Lottes, ,The State of the Art'. Stand und Perspektiven der ,Intellectual History', in: Frank-Lothar Kroll (Hrsg.), Neue Wege der Ideengeschichte. Festschrift für Kurt Kluxen zum 85. Geburtstag. Paderborn u. a. 1996, 27-45, hier 45.

24 Briefe Johanns von Neumarkt. Ed. Paul Piur. Mit einem Anhang: Ausgewählte Briefe an Johann von Neumarkt, urkundliche und briefliche Zeugnisse zu seinem Leben. (Vom Mittelalter zur Reformation, Bd. 8.) Berlin 1937, Nr. 48, 79-83 (im Folgenden auch bezeichnet als ,Brief 48'). dictandi' des Bernhard von Meung zahlreiche Musterbriefe und Formulare mit Namen von Angehörigen der Prager Hofgesellschaft enthält (München, Bayerische Staatsbibliothek, Clm 96, Bl. $\left.66^{\mathrm{r}}-67^{\mathrm{r}}\right){ }^{25}$ Unter anderem treten Karl IV., sein Sohn Wenzel, Johann von Neumarkt und Cola di Rienzo als Verfasser auf. In ihrem Kernbestand dürfte die Sammlung auf Angehörige der Prager Kanzlei zurückgehen; der Schlussteil beinhaltet Themen, welche die Prager Universität betreffen. ${ }^{26}$ Die Autorzuschreibungen sind im Einzelnen nicht gesichert, doch sind mit den überlieferten Texten typische Themen und Aussageformen der Prager Hofkultur zu greifen.

Ein Bestreben nach sprachlicher Eleganz ist dabei unverkennbar. Es orientiert sich, wenn auch mit wechselndem Erfolg, am Stil der Italiener Petrarca und Cola di Rienzo, die sich zeitweilig am Prager Hof aufhielten und ihre politischen Reformideale in einem an den römisch-antiken Autoren der Republik und Kaiserzeit geschulten Latein vortrugen. ${ }^{27}$

25 Die Handschrift befand sich im 16. Jahrhundert im Besitz des Ulmer Humanisten Johann Albrech Widmanstetter (1506-1557) und wurde nach dessen Tod durch Herzog Albrecht von Bayern erworben. Vgl. Karl Halm / Georg Laubmann, Catalogus Codicum Latinorum Bibliothecae Regiae Monacensis. Editio altera emendatior, Bd. 1.1: Clm 1-2329. (Catalogus Codicum Manu Scriptorum Bibliothecae Regiae Monacensis, Bd. 3.1.) München 1868, 25f.; Otto Hartig, Die Gründung der Münchener Hofbibliothek durch Albrecht V. und Johann Jakob Fugger. (Abhandlungen der Königlich Bayerischen Hofbibliothek durch Albrecht V. und Johann Jakob Fugger. (Abhandlungen der Königlich Bayerischen
Akademie der Wissenschaften. Philosoph.-philolog. u. hist. Kl., Bd. 28.3.) München 1917, 135, 188; Briefe Johanns von Neumarkt. Ed. Piur (wie Anm. 24), XXII-XXIV; Briefwechsel des Cola di Rienzo Ed. Konrad Burdach/ Paul Piur. (Vom Mittelalter zur Reformation, Bd. 2.1-5.) Berlin 1912-1929, Bd. 2, 272-276; Hans Striedl, Die Bücherei des Orientalisten Johann Albrecht Widmanstetter, in: Han Joachim Kissling / Alois Schmaus (Hrsg.), Serta Monacensia. Franz Babinger zum 15. Januar 1951 als Festgruß dargebracht. Leiden 1952, 200-244, hier 217; Johannes Meisenzahl, Die Bedeutung des Bernhard von Meung für das mittelalterliche Notariats- und Schulwesen, seine Urkundenlehre und deren Überlieferung im Rahmen seines Gesamtwerkes. Diss. phil. (masch.). Würzburg 1960, Bd. 1 85f., 199; Charles Vulliez, Un nouveau manuscrit ,parisien' de la ,Summa dictaminis' de Bemard de Meung et sa place dans la tradition manuscrite du texte, in: Revue d'histoire des textes 7, 1977, 133151, hier 134; Franz Josef Worstbrock / Monika Klaes / Jutta Lütten, Repertorium der Artes dictand des Mittelalters, Teil 1: Von den Anfängen bis um 1200. (Münstersche Mittelalterschriften, Bd. 66.) München 1992, Nr. 9.14, 51f.; Hans-Martin Schaller, Handschriftenverzeichnis zur Briefsammlung des Petrus de Vinea. (Monumenta Germaniae Historica. Hilfsmittel, Bd. 18.) Hannover 2002, 181f. Zu Widmanstetters Bibliothek zuletzt Helga Rebhan, Die Bibliothek Johann Albrecht Widmanstetters, in: Alois Schmid (Hrsg.), Die Anfänge der Münchener Hofbibliothek unter Herzog Albrecht V. München 2009, 112-131.

26 Vgl. Briefe Johanns von Neumarkt. Ed. Piur (wie Anm. 24), XXIII.

27 Vgl. zu Petrarca: Petrarcas Briefwechsel mit deutschen Zeitgenossen mit einem Anhang: Petrarcas sonstige Berichte und Urteile über Deutschland. Ed. Paul Piur. (Vom Mittelalter zur Reformation, Bd. 7.) Berlin 1933; Petrarch. The Revolution of Cola di Rienzo. Ed. Mario Emilio Cosenza. New York ${ }^{3}$ 1996; Francesco Petrarca, Aufrufe zur Errettung Italiens und des Erdkreises. Ausgewählte Briefe Ed. Berthe Widmer. Basel 2001, bes. 369-571; Francesco Petrarca, Lettere all'imperatore. Carteggio con la corte di Praga. 1351-1364. Ed. Ugo Dotti. Reggio Emilia 2008; Seibt, Karl IV. Kaiser (wie Anm. 5), bes. 215-221; Ugo Dotti, Vita di Petrarca. Roma / Bari 1987, bes. 227-229, 301-309, 313 317. Eva Schlotheuber, Petrarca am Hof Karls IV und die Rolle der Humanisten, online: Hein rich C. Kuhn (Hrsg.), Interdisziplinäre Vortragsreihe durch Münchner Gelehrte zur Feier der 700. Wiederkehr 
Insbesondere Johann von Neumarkt (um 1315-1380), seit 1353 Vorsteher der kaiserlichen Kanzlei und ab 1364 Bischof von Olmütz, ${ }^{28}$ zeigt dabei ein ausgeprägtes Interesse an sprachlicher Kunstfertigkeit, ja an der Zurschaustellung und Thematisierung von Sprache. Dies wird etwa in einer Aussage Johanns deutlich, in der er erklärt, dass er zu Ehren des Kaisers „das Gold und Silber der Sprache verfeinert habe“ (aurum tamen et argentum ligwe pro inuictissimi Cesaris ampliandis honoribus [...] expoluit). ${ }^{29}$ Mit seinen zahlreichen für Karl IV. und Angehörige der Adelsgesellschaft angefertigten Übersetzungen praktizierte Johann diese Sprachpflege auch im Idiom des Deutschen, so u. a. mit dem ,Buch der Liebkosung' (einer Übertragung der pseudo-augustinischen ,Soliloquia'), dem als Briefzyklus konzipierten ,Hieronymusleben“ und einer Vielzahl von Gebetstexten.

In diesen Schriften kommt eine Spiritualität zum Ausdruck, die für das geistige Leben am Prager Hof und in Böhmen charakteristisch ist. Verschiedene der Vorlagentexte

des Geburtstags Francesco Petrarcas im Sommersemester 2004, München 2004, Ludwig-MaximilianUniversität München, http://www.phil-hum-ren.uni-muenchen.de/SekLit/P2004A/Schlotheuber.htm (Zugriff: 10.07.2012); Ugo Dotti, Petrarch in Bohemia. Culture and Civil Life in the Correspondence between Petrarch and Johann von Neumarkt, in: Karl A.E. Enenkel / Jan Papy (Hrsg.), Petrarch and his Readers in the Renaissance. (Intersections. Yearbook of early Modern Studies, Bd. 6.) Leiden / Boston 2006, 73-87. Zu Cola di Rienzo: Paul Piur, Cola di Rienzo. Darstellung seines Lebens und seines 2006, 73-87. Zu Cola di Rienzo: Paul Piur, Cola di Rienzo. Darstellung seines Lebens und seines
Geistes. Wien 1931, bes. 156-177 (forschungsgeschichtlich überholt und in den Rahmentexten politisch etwas tendenziös); Bartoš, Dantova ,Monarchie‘ (wie Anm. 8); Josef Macek, Cola di Rienzo. (Československá společnost pro šiření politických a vědeckých znalostí. Portréty, Bd. 13.) Praha 1965; Seibt, Karl IV. Kaiser (wie Anm. 5), bes. 207-215; Joachim Wider, Cola di Rienzo, in: Seibt, Karl IV. und sein Kreis (wie Anm. 5), 111-144; Clifton-Everest, Johann von Neumarkt (wie Anm. 8); Tommaso di Carpegna Falconieri, Cola di Rienzo. Roma 2002, bes. 151-172; Ronald G. Musto, Apocalypse in Rome. Cola di Rienzo and the Politics of the New Age. Berkeley / Los Angeles / London 2003, bes. 269-301. Zu beiden Nechutová, Lateinische Literatur (wie Anm. 8), 174f.

28 Vgl. Jean Lulvès, Die Summa cancellariae des Johann von Neumarkt. Eine Handschriftenuntersuchung über die Formularbücher aus der Kanzlei Kaiser Karls IV., Diss. phil. Berlin 1891; Klapper, Johann von Neumarkt (wie Anm. 7); Ernst Schwarz, Johann von Neumarkt, in: Karl Bosl (Hrsg.), Lebensbilder zur Geschichte der böhmischen Länder. München/Wien 1974, Bd. 1, 27-47; Josef Bujnoch, Johann von Neumarkt als Briefschreiber, in: Seibt, Karl IV. und sein Kreis (wie Anm. 5), 67-76; Werner Höver, Art. Johann von Neumarkt, in: Die deutsche Literatur des Mittelalters - Verfasserlexikon, Bd. 4. Berlin / New York ${ }^{2} 1983$, 686-695; Clifton-Everest, Johann von Neumark (wie Anm. 8); Peter Ochsenbein, Johann von Neumarkt als geistlicher Schriftsteller, in: Joachim Heinzle / L. Peter Johnson / Gisela Vollmann Profe (Hrsg.), Literatur im Umkreis des Prager Hofs der Luxemburger. Schweinfurter Kolloquium 1992. (Wolfram Studien, Bd. 13.) Berlin 1994, 67 Vollmann, Johann von Neumarkt Lateinischer und dersch gang Harms / Jan-Dirk Müller (Hrsg.), Mediävistische Komparatistik. Festschrift für Franz Josef Worstbrock zum 60. Geburtstag. Stuttgart / Leipzig 1997, 151-162; Dotti, Petrarch in Bohemia (wie Anm. 27); Nechutová, Lateinische Literatur (wie Anm. 8), 176-183; Ricarda Bauschke, Johann von Neumarkt: ,Hieronymus-Briefe'. Probleme von Epochengrenzen und Epochenschwellen am Beispiel des Prager Frühhumanismus, in: Nicola McLelland / Hans-Jochen Schiewer / Stefanie Schmit (Hrsg.), Humanismus in der deutschen Literatur des Mittelalters und der Frühen Neuzeit. XVIII Anglo-German Colloquium, Hofgeismar 2003. Tübingen 2008, 257-271.

29 Briefe Johanns von Neumarkt. Ed. Piur (wie Anm. 24), Nr. 37, 66-68, Z. $17-19$. dürften Johann durch seine Kontakte zu den italienischen Augustiner-Eremiten zugänglich geworden sein (so die ,Soliloquia'), andere (wie das ,Hieronymusleben', 1368/69) hat er anlässlich von Italienaufenthalten in Begleitung des Kaisers erworben. ${ }^{30}$ Eine intensiv praktizierte Frömmigkeit prägt auch das kaiserliche Selbstverständnis, das sich in zahlreichen Briefen des Kaisers und seiner Umgebung, aber auch in einer unter Karls Namen verfassten Autobiographie (,Vita Caroli Quarti') bekundet. ${ }^{31}$ Fassbar wird diese vergeistlichte Mentalität zudem in einem ausgeprägten Reliquienkult und in den von Karl IV. in Auftrag gegebenen Bauten, namentlich in der Prager St.-Veits-Kathedrale und in der Privatresidenz von Burg Karlstein mitsamt den dafür angefertigten Kunstwerken. ${ }^{32}$

Die auf diese Weise medialisierte Frömmigkeit ist zweifellos authentisch; gleichwohl sollte nicht übersehen werden, dass die ins Theokratische reichende Spiritualisierung des Kaiseramtes auch eine wohlkalkulierte Strategie darstellte. Anders als sein Vorgänger Ludwig der Bayer vermied Karl in der konfliktträchtigen Frage nach dem Verhältnis von kaiserlicher und päpstlicher Gewalt die Auseinandersetzung mit der Kurie und war stattdessen um einen diplomatischen Ausgleich bemüht. ${ }^{33} \mathrm{Zu}$ diesem Vorgehen aber gehörte eine Sakralisierung des eigenen kaiserlichen Selbstverständnisses. Die von der Person des Kaisers ausgehende Spiritualität hatte also auch eine unverkennbar politische Dimension. ${ }^{34}$ Der institutionellen und theologischen Rechtfertigung dieser Haltung dienten

30 Vgl, Klapper, Johann von Neumarkt (wie Anm. 7), 20; 37.

31 Vgl. die Edition und deutsche Übersetzung der lateinischen Fassung: Vita Caroli Quarti. Die Autobiographie Karls IV. Ed. Eugen Hillenbrand. Stuttgart 1979. Dazu zuletzt Hans-Joachim Behr, Herrschaftsverständnis im Spiegel der Literatur. Die ,Vita Caroli Quarti', in: Joachim Heinzle / L. Peter Johnson / Gisela Vollmann-Profe (Hrsg.), Literatur im Umkreis des Prager Hofs der Luxemburger. Schweinfurter Kolloquium 1992. (Wolfram Studien, Bd. 13.) Berlin 1994, 81-91; Hergemöller, Cogor adversum te (wie Anm. 5), 233-253; Eva Schlotheuber, Die Autobiographie Karls IV. und die mittelalterlichen Vorstellungen vom Menschen am Scheideweg, in: Historische Zeitschrift 281, 2005, 561-591; Nechutová, Lateinische Literatur (wie Anm. 8), 170f.; Anke Paravicini-Ebel, Die Vita Karls IV., ein ,Ego-Dokument‘?, in: Deutsches Archiv für Erforschung des Mittelalters 63, 2007, 101-109, jeweils mit weiterer Literatur.

32 Vgl. Stejskal / Neubert, Karl IV. (wie Anm. 5); Barbara Drake Böhm, Der gläubige Herrscher, in: Fajt, Karl IV. Kaiser von Gottes Gnaden (wie Anm. 5), 137-171; Schlotheuber, Ausbau Prags (wie Anm. 5), 609-613; Fajt / Langer, Kunst als Herrschaftsinstrument (wie Anm. 5), darin bes. die Beiträge von Zoë Opačić, Architecture and religious experience in 14th-century Prague, 136-149, und Jiř́ Fajt, Karlstein Revisited. Überlegungen zu den Patrozinien der Karlsteiner Sakralräume, 250288; Němec, Kulturlandschaft und Staatsidee (wie Anm. 5); Zoë Opačić (Hrsg.), Prague and Bohemia. Medieval Art, Architecture and Cultural Exchange in Central Europe. (The British Archaeological Association. Conference Transactions, Bd. 32.) Leeds 2009, darin bes. den Beitrag von Milada Studničková, Karlstein Castle as a Theological Metaphor, 168-182.

33 Vgl. Ludwig Schmugge, Kurie und Kirche in der Politik Karls IV., in: Seibt, Kaiser Karl IV. Staatsmann und Mäzen (wie Anm. 5), 73-87; Seibt, Karl IV. Kaiser (wie Anm. 5), 335-342.

34 Vgl. Reinhard Schneider, Karls IV. Auffassung vom Herrscheramt, in: Theodor Schieder (Hrsg.), Beiträge zur Geschichte des mittelalterlichen deutschen Königtums. (Historische Zeitschrift. Beihefte, Bd. 2.) München 1973, 122-150; Seibt, Karl IV. Kaiser (wie Anm. 5), 245; Schlotheuber, Autobiographie Karls IV. (wie Anm. 31), 586-590. 
zahlreiche von Karl veranlasste Maßnahmen, so die Erhebung Prags zum Erzbistum, die Gründung der Prager Universität nach dem Vorbild der theologischen Hochburg Paris und die in panegyrischen Texten geläufige Inszenierung des Kaisertums als Quelle herrscherlichen Heils, die sich in die einzelnen Instanzen des Staatswesen ergießt. ${ }^{35}$

Unter diesem Eindruck steht auch der an Karl adressierte Brief, welcher, obschon sich der Schreiber nicht namentlich nennt, von Johann von Neumarkt oder einem Gesinnungsgenossen aus dessen Umgebung stammen dürfte; als Verfasser tritt ein nicht näher genannter Bischof in Erscheinung (Episcope, Z. 65; presulatus, Z. 72) ${ }^{36}$ Der Brief folgt den in den mittelalterlichen Briefstellern bzw., Artes dictaminis'vorgegebenen Gliederungspunkten, welche sich an die in Ciceros Schriften überlieferten Redeteile anlehnen: salutatio - exordium (mit der captatio benevolentiae) - narratio - petitio - confirmatio confutatio - conclusio. ${ }^{37}$

35 Vgl. zur Erhebung Prags zum Erzbistum und zur Gründung der Prager Universität Roderich Schmidt, Begründung und Bestätigung der Universität Prag durch Karl IV. und die kaiserliche Privilegierung von Generalstudien, in: Patze, Kaiser Karl IV. (wie Anm. 5), 695-719; Schmugge, Kurie und Kirche (wie Anm. 33), 74; Seibt, Karl IV. Kaiser (wie Anm. 5), 179-185; Barbara Drake Böhm Die Universität von der Gründung bis zum Kuttenberger Dekret, in: Fajt, Karl IV. Kaiser von Gottes Gnaden (wie Anm. 5), 263-275; František Šmahel, Die Präger [sic!] Universität im Mittelalter. Gesammelte Aufsätze. The Charles University in the Middle Ages. Selected studies. (Education and society in the Middle Ages and Renaissance, Bd. 28.) Leiden 2007, darin bes. den Beitrag Die Anfänge der Prager Universität. Kritische Reflexionen zum Jubiläum eines ,nationalen Monuments‘ , 3 50. - Zur Emanationsmetaphorik in der zeitgenössischen Dichtung, etwa bei Heinrich von Mügel vgl. Hubert Herkommer, Kritik und Panegyrik. Zum literarischen Bild Karls IV (1346-1378), in:

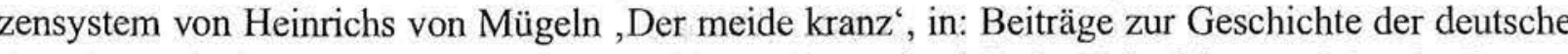
Sprache und Literatur 103, 1981, 63-91, hier 74f.; Michael Stolz, Heinrichs von Mügeln Fürstenpreis auf Karl IV. - Panegyrik, Herrschaftslegitimation, Sprachbewusstsein in: Joachim Heinzle / L. Peter Johnson / Gisela Vollmann-Profe (Hrsg.), Literatur im Umkreis des Prager Hofs der Luxemburger. Schweinfurter Kolloquium 1992. (Wolfram-Studien, Bd. 13.) Berlin 1994, 106-141, bes. 112-114; Annette Volfing, Heinrich von Mügeln, ,Der meide kranz'. A Commentary. (Münchener Texte und Untersuchungen, Bd. 111.) München 1997, 18f., 190

36 Zitate und Zeilenangaben im Folgenden nach: Briefe Johanns von Neumarkt. Ed. Piur (wie Anm. 24), Nr. 48, 79-83; vgl. Anhang 1. Eine moderne deutsche Übersetzung befindet sich in Anhang 2. Piur gibt als Entstehungszeit die Jahre „1376-1378?“ an (ebd, 79). Doch könnte der Text mit seinen wörtlichen und thematischen Bezügen zur ,Goldenen Bulle', zu Heinrichs von Mügeln ,Der meide kranz $z^{\star}$ und dem anonymen Dialog ,Cogor adversum te', Texten, die kurz nach 1355 entstanden sind (vgl. unten 280f., 283f.), auch etwa zwanzig Jahre älter sein.

37 Vgl. James Jerome] Murphy, Rhetoric in the Middle Ages. A History of Rhetorical Theory from Saint Augustine to the Renaissance. Berkeley/Los Angeles/London 1974, 224f.; die Einleitung von Smolak in: Erasmus von Rotterdam, De conscribendis epistolis. Anleitung zum Briefeschreiben (Auswahl). Ed. Kurt Smolak. (Erasmus von Rotterdam. Ausgewählte Schriften, Bd. 8.) Darmstad 1980, IX-LXXXVI, bes. XXVII- XXVIII; Martin Camargo, Ars dictaminis. Ars dictandi. (Typologie des sources do moyen âge occidental, Fasc. 60, A-V. A.2*.) Turnhout 1991, 22f. In der in Clm 96 , fol $17^{\vee}-47^{\mathrm{r}}$, überlieferten Ars dictandi` des Bernhard von Meung (späteres 12. Jh.) werden die fünf Teile folgendermaßen benannt: salutacio - prohemium bzw. prouerbium - narracio - peticio -
Auf die einleitende Salutatio (Z. 1) folgt das Exordium mit der Captatio benevolentiae (Z 1-19), welche in der Tradition antiker Rhetorik die Geneigtheit, Aufmerksamkeit und Gelehrigkeit des Adressaten zu erheischen sucht (benivolum, attentum und docilem facere, fassbar in den Abschnitten Z. 1-7, 8-12, 12-19). ${ }^{38}$ In diesem Zusammenhang sei auf das der Salutatio vorangestellte Zitat aus dem Hebräerbrief (Vivus est sermo tuus, Z. 1, nach $\mathrm{Hbr}$ 4,12: vivus est enim Dei sermo) verwiesen, das mit seiner die Sprachhandlung betonenden Aussage auch im Titel des vorliegenden Beitrags steht. Im Rahmen des Briefs wird es in die erwähnte Emanationsmetaphorik überführt: Die im Paulusbrief evozierte "lebendige Rede" Gottes wird hier dem Kaiser zugesprochen; von diesem heißt es, dass seine Rede ,aus einem wahrhaft glückseligen Quell göttlichen Wesens“ hervorsprudle ( $e$ beato quodam diuinitatis fonte scaturiens, Z. 1f.) und dass sie bis zur „Gesinnung [s]eines demütigen und unwürdigen Geschöpfes“, d. h. jener des Briefschreibers, vordringe (mentem humilis et indigne creature tue, Z. 9)

Ebenfalls noch im Rahmen des Exordiums, genauer in jenem Abschnitt, der an die Gelehrigkeit des Adressaten appelliert (docilem facere), erfolgt eine Absage an die auf menschlicher Erkenntniskraft und Vernunft (vgl. intellectus, racio, Z. 14) gründende

conclusio, wobei der Autor betont, dass die Teile der salutacio und narracio zum festen Bestand des Briefes gehören, während die anderen auch wegfallen können (vgl. fol.. 17 $7^{\mathrm{v}}$, wo die conclusio als condicio bezeichnet wird; als conclusio auf fol. $\left.23^{\mathrm{r} / \mathrm{v}}\right)$. Im Einzelnen definiert Bernard die Briefteile wie folgt: Salutacio est breuis oracio que mittentis affectum continet et a statu non dissidet personarum (fol. $17^{v}$ ) - Prohemium siue prouerbium est captacio beneuolencie (fol. $23^{\mathrm{T}}$ ) - Narracio est (fol. 23') - Peticio est oracio per quam petimus aliquid fieri uel non fieri (fol. $\left.23^{v}\right)$ - Conclusio est terminalis oracio per quam ostendimus que utilitas et que inutilitas ex admissa peticione sequi debeat (fol. $23^{v}$ ). Zur Begrifflichkeit auch die diversen ,Artes dictandi` bei Ludwig Rockinger, Briefsteller und formelbücher des eilften bis vierzehnten jahrhunderts, 2 Teile. (Quellen und Erörterungen zur bayerischen und deutschen Geschichte, Bd. 9.) München 1863-1864. Nachdruck New York 1961, bes. die im Wortlaut eng verwandte, Ars dictandi aus Orleans' (wenige Jahre vor der ,Ars dictandi' des Bernhard von Meung, ca. 1180/1181, entstanden), 95-114, v. a. Kap. III-VII, 103, 108f.; dazu auch Meisenzahl, Bedeutung des Bernhard von Meung (wie Anm. 25), Bd. 1, 57f.; ferner, mit fragwürdigen Datierungen, Murphy, Rhetoric in the Middle Ages (wie oben), 227f. Zur Rezeption von Bernhards ,Ars dictandi` im deutschsprachigen Raum ausführlich Meisenzahl, Bedeutung des Bernhard von Meung (wie Anm. 25), Bd. 1, 154-199. Zur Terminologie der Briefteile auch die Einträge bei Joachim Knape / Armin Sieber, Rhetorik-Vokabular zur zweisprachigen Terminologie in älteren deutschen Rhetoriken. (Gratia. Bamberger Schriften zur Renaissance-Forschung, Bd. 34.) Wiesbaden 1998.

$38 \mathrm{Vgl}$. Comificii Rhetorica ad C. Herennium. Ed. Gualtiero Calboli. (Edizioni e saggi universitari di filologia classica, Bd. 11.) Bologna 1969, 97f., lib. I, cap. IV,6-V,8; ähnlich: M. Tulli Ciceronis scripta quae manserunt omnia, fasc. 2: Rhetorici libri duo qui vocantur De Inventione. Recognovit $E[$ duard] Stroebel. (Bibliotheca Teubneriana.) Leipzig 1915, ND Stuttgart 1965, 18f., lib. I, cap. 15,20. Zum Traditionshorizont auch den Kommentar in: Dante Alighieri, Das Schreiben an Cangrande della Scala. Ed. Thomas Ricklin. (Dante Alighieri, Philosophische Werke, Bd. 1. / PhiloCangische Bibliothek, Bd. 463) H Ricklin. (Dante Alighien, Philosphische Weike, Bd 1./ PheMiddle Ages (wie Anm. 37), 205f. u. ö. 
philosophische und wissenschaftliche Betätigung. Neben der Philosophie (philosophia contempta, Z. 13) nennt der Verfasser Verfahren der Logik und Mathematik (Z. 14-16), von denen er sich zugunsten metaphysischer Studien (supernaturalem philosophiam, Z. 13) ${ }^{39}$ und ihrer auf die göttliche Allmacht verweisenden Ziele (inuicta potencia [...] vniuersa, Z. 18f.) abwenden wolle (conuertere, Z. 14). ${ }^{40}$

Der nunmehr folgende Hauptteil des Briefs, die Narratio (Z. 20-62), besteht aus einem längeren Abschnitt, in welchem der Verfasser die personifizierte Natura aus der Dichtung ,De planctu Naturae' des Alanus ab Insulis (als Prosimetrum verfasst um 1160/70) auftreten lässt. ${ }^{41}$ Der Prosapassus ist durch das einleitende Verbum fingo (,ich erdichte“, „ich ersinne“, Z. 20) und den Hinweis, dass Natura als Personifikation auftrete (assumpto sibi racionabili persona, Z. 20), klar als fiktiv markiert, ${ }^{42}$ zudem wird die Autorschaft des Alanus (Alano teste, Z. 21) mittels einer Figura etymologica der Wörter testis, testimonium und attestari hervorgehoben (Z. 21f.). Das Verfahren, die fingierte Rede einer abwesenden Person oder Personifikation in den Brief aufzunehmen und damit die eigene Rede zu hybridisieren, ist im Kontext der Prager Hofkultur durchaus üblich. Ein offenbar wirkmächtiges Vorbild liefert Petrarca, der Karl IV. zur Übernahme des Kaiseramtes durch die Krönung in Rom und zur Wiederherstellung des römischen Imperiums ermahnt,

39 In der Handschrift steht anstelle des Ausdrucks philosophiam der ebenfalls plausible Begriff phisicam.

40 Zum Begriff der im christlichen Kontext besonders in Augustins ,Confessiones' vorgeprägten Conversio (,Umkehr') vgl. Alois M[aria] Haas, Streiflichter auf die Struktur der Bekehrung im Geiste Augustins, in: Johannes Brantschen/ Pietro Selvatico (Hrsg.), Unterwegs zur Einheit. Festschrift für Heinrich Stirnimann. Freiburg (Schweiz) / Freiburg i. Br. / Wien 1980, 225-240 Kurt Flasch, Augustin. Einführung in sein Denken. Stuttgart ${ }^{2} 1994,43-52$. - Zu Conversio-Motiven in der Vita Caroli Quarti Schlotheuber, Autobiographie Karls IV. (Anm. 31), 583sio-Motiven in der Vita Caroli Quarti Schlotheuber, Autobiographie Karls IV. (Anm. 31), 583-
586 („Umkehrgeschichte“). Zur Stelle in Brief 48 auch Herkommer, Kritik und Panegyrik (wie Anm. 35), 111, Anm. 79; Christoph Huber, Die Aufnahme und Verarbeitung des Alanus ab Insulis in mittelhochdeutschen Dichtungen. Untersuchungen zu Thomasin von Zerklære, Gottfried von Straßburg, Frauenlob, Heinrich von Neustadt, Heinrich von St. Gallen, Heinrich von Mügel und Johannes von Tepl. (Münchener Texte und Untersuchungen, Bd. 89.) München / Zürich 1988, 260; Hergemöller, Cogor adversum te (wie Anm. 5), 82f.

41 Vgl. Alanus ab Insulis, De planctu naturae. Ed. Nikolaus M. Häring, in: Studi Medievali, ser. 3 , 19.2, 1978, 797-879; engl. Übersetzung: Alan of Lille, The Plaint of Nature. Translation and Commentary by James J. Sheridan. (Mediaeval sources in translation, Bd. 26.) Toronto 1980. Dazu Johannes Köhler, Natur und Mensch in der Schrift ,De Planctu Naturae' des Alanus ab Insulis, in: Albert Zimmermann / Andreas Speer (Hrsg.), Mensch und Natur im Mittelalter, Bd. 1. (Miscellanea mediaevalia, Bd. 21.1) Berlin / New York 1991, 57-66; Mechthild Modersohn, Natura als Göttin im Mittelalter. Ikonographische Studien zu Darstellungen der personifizierten Natur. (Acta humaniora. Mittelalter. Ikonographische Studien zu Darstellungen der personifizierten Natur. (Acta humaniora.
Schriften zur Kunstwissenschaft und Philosophie.) Berlin 1997, 30-33 u. ö.; George D. Economou, The Goddess Natura in Medieval Literature. Notre Dame ${ }^{2} 2002,72-103$.

42 Der fiktionale Status wird auch in ,Artes dictandi` wie jener des Bernhard von Meung thematisiert, wo die Narratio u. a. als exposicio rei (...) prout geste (,Darstellung eines gleichsam geschehene Sachverhalts") beschrieben wird. vgl. oben, Anm. 37. - Zur Stelle auch Huber, Aufnahme und Verarbeitung (wie Anm. 40), 260f. (,rhetorische Personifikation“); Hergemöller, Cogor adversum te (wie Anm. 5), 83 (,,literarische[n] Fiktion“). indem er - ebenfalls mit dem Signalwort fingere - die personifizierte urbs Romana auftreten lässt, in deren Rede er zudem eine Ansprache von Heinrich VII., Karls kaiserlichem Großvater, aufnimmt. ${ }^{43}$ Wie bei Petrarca schließt auch der vorliegende Brief mit dieser fingierten Fremdrede, ohne dass der Verfasser noch einmal als Sprecher in Erscheinung träte. Allerdings folgt hier auf das Alanus-Zitat ein längerer Abschnitt, den der Verfasser in eigenen Worten hinzugefügt hat (Z. 63-95).

In der nach Alanus' ,De planctu Naturae“ zitierten, dort auf einer intradiegetischen Ebene an den Dichter gerichteten Rede ${ }^{44}$ verdeutlicht Natura, dass sie dem schöpferischen Wirken Gottes unterstellt ist. Wie es an mehreren Stellen von ,De planctu Naturae heißt, fungiert Natura als vicaria Dei, als "Stellvertreterin Gottes“ ${ }^{45}$ Diese Aufgabe wird im zitierten Abschnitt mittels der Bezeichnungen humilis discipula („demütige Schülerin“, Z. 23f.) und obstetrix („Hebamme“, Z. 42) verdeutlicht: Während Gott allein die schöpferische Allmacht zukommt - vergegenwärtigt in den zahlreichen, wiederum als Figura etymologica gestalteten Wortwiederholungen von operari, opus und opifex (Z. 24-31) ist Natura Ausführende des göttlichen Schöpfungsplans - operans operantis (Z. 24) ${ }^{46} \mathrm{Als}$ solche kommt es ihr zu, den Menschen ins physische Sein, aber auch in den Tod zu führen; sie geleite (oder, wie es heißt: „rufe“) den Menschen a non esse (...) ad esse und ad mortem (Z. 38f.). Allein Gott hingegen komme es zu, den Menschen in einer zweiten Geburt zum Leben (ad vitam, Z. 40) zu erschaffen. Im Zuge dieser Argumentation wird wiederholt hervorgehoben, dass es allein der vom Glauben geleiteten Theologie (Z. 34, 47f.) zukomme, diese von Gott gewährte Neugeburt zu erklären, während, so die implizite Aussage, die von der Natur handelnde Wissenschaft (physica $)^{47}$ mit ihren auf der Vernunft gründenden Erklärungen dies nicht zu leisten vermöge.

43 Vgl. Petrarcas Briefwechsel. Ed. Piur (wie Anm. 27), Nr. 1, 1-11, ausgestellt am 24. Februar (1351?) in Padua (= Rerum familiarum X,1); deutsche Übersetzung in: Petrarca, Aufrufe zur Errettung Italiens. Ed. Widmer (wie Anm. 27), 370-383; italienische Übersetzung in: Petrarca, Lettere all'imperatore. Ed. Dotti (wie Anm. 27), 29-36. Vgl. auch Dotti, Vita di Petrarca (wie Anm. 27), 227-229. Die Rede der als matrona bezeichneten Stadt Rom wird eingeleitet mit den Worten: Finge nunc animo almam te Romane urbis effigiem uidere. Cogita matronam (...) ita tecum loqui: ,Ego, Cesar, ne despexeris etatem meam, multa olim potui, multa gessi. (.... ‘. Heinrichs VII. Rede, die den Schluss des Briefs bildet, wird von der sprechenden urbs Romana folgendermaßen eingeführt: Henricus, eterne memorie serenissimus auus tuus. (...) Spectat ille nunc celorum perpes incola et ab alto considerat gressus tuos, dies computat horasque dinumera teque mecum increpitans alloquitur: Nepos amantissime (. ). Incipe. Ne moreris. Et nostri esse mortalem. I celer et gaudentia Alpium claustra transcende. Roma sponsum, sospitatorem suum uocat Italia et tuis pedibus tangi cupit. (...).

44 Vgl. Alanus ab Insulis, De planctu naturae. Ed. Häring (wie Anm. 41), 829,129-830,165.

45 Vgl. Alanus ab Insulis, De planctu naturae. Ed. Häring (wie Anm. 41), 825,21, 827,80, 840,224 u. ö. Zur Verwendung in Brief 48 auch Hergemöller, Cogor adversum te (wie Anm. 5), 68f.

46 Dazu auch Economou, Goddess Natura (wie Anm. 41), 78f.; Köhler, Natur und Mensch (wie Anm. 41), 58-60.

47 Vgl. oben, Anm. 39. 
Die auf das Alanus-Zitat folgende Petitio (Z. 63-78) ermahnt den - wie es heißt „ahnungslosen Bischof" (imprudens Episcope, Z. 65) neuerlich zur ,Umkehr" (conuerte, Z. 68, vgl. auch Z. 14): $:^{48}$ Er möge die Augen seiner Erkenntniskraft von verschmutzter Öde abwenden und sie in glückseliger Anschauung auf die lieblichen, immergrünen Haine des Paradieses richten (a squalenti sterilitate declinans oculos tui intellectus ad amena paradisi florencia semper nemora ymaginacione beata conuerte! Z. 66-68). Die an den Bischof gerichtete Aufforderung wertet die Verstandeskräfte (oculos intellectus, Z. 66f.) gegenüber visionärer Vorstellungskraft (ymaginacio beata) ab und bewegt sich damit genau in dem eingangs beschriebenen Spannungsfeld von Wissen und Religion, von Vernunft und Glauben. Das anstelle rationaler Betätigung in gläubiger Andacht Geschaute wird durch Worte zum Ausdruck gebracht (amena paradisi florencia semper nemora, Z. 67), in denen Verse aus dem ,Carmen Paschale des Sedulius (5. Jh.) nachklingen, die ihrerseits im einleitenden Gebet der, Goldenen Bulle von 1356, dem bedeutenden unter Karl IV. erarbeiteten Verfassungstext für das Reich, erscheinen. ${ }^{49}$ Mit der auf diese Weise beschriebenen Haltung soll der Adressat seine wissenschaftlichen Neigungen aufgeben. Ausdrücklich genannt wird die in Ägypten erfundene und von den Griechen weiterentwickelte Astronomie (Z. 68f.). Statt sich diesen Interessen zu widmen, solle der Bischof lieber auf den Spuren Gottes wandeln, der hier als „ewiger Kaiser“ (imperator eternus) bezeichnet wird (Z. 69f.). Auffällig ist, wie diese Apostrophierung mit jener des irdischen Kaisers korreliert, welcher wenig später als Autorität in Erscheinung tritt, als inuictissimus Cesar, mundi monarcha (Z. 75), als Autorität, die - immer noch in Naturas Worten - den Bischof zur Aufgabe der Wissenschaft veranlassen will. Das Attribut inuictus, ,unbesiegt“ oder wohl besser „unbesiegbar“, begegnet zunächst in der Begrüßung des Kaisers (Z. 1), erscheint dann bezogen auf die Allmacht Gottes - inuicta potencia (...) vniuersa - (Z. 18f.) und wird schließlich, nunmehr im Superlativ, wiederum dem Kaiser zugesprochen (Z. 75); auf diese Weise ist der Brief von Motivresponsionen durchsetzt. Auffällig ist ferner, wie sich der Verfasser, wenn er denn mit dem als Episcope apostrophierten Bischof iden-

48 Dazu oben, 277.

49 Vgl. Sedulii Opera omnia. Una cum excerptis ex Remigii expositione in Sedulii Paschale Carmen Ed. Iohannes Huemer. (Corpus scriptorum ecclesiasticorum Latinorum, Bd. 10, Ed. 2.) Wien ${ }^{2} 2007$, 19, lib. I, v. 53f:: sed amoena uirecta/ Florentum semper nemorum; Die Goldene Bulle vom 10. Januar und 25. Dezember 1356, lateinisch und frühneuhochdeutsch, in: Dokumente zur Geschichte des Deutschen Reiches und seiner Verfassung 1354-1356. Ed. Wolfgang D. Fritz. (Monumenta Germaniae Historica. Constitutiones et acta publica imperatorum et regum, Bd. 11.) Weimar 1978-1992, 535-633, hier 560, v. 8f.: per amena virecta/ Florentum semper nemorum. Dazu Hergemöller, Cogor adversum te (wie Anm. 5), 18, 69, mit Hinweisen auf die weitere Verwendung im Prager Kontext, und ebd., 126-134, mit Quellenangaben zum Vorgebet der ,Goldenen Bulle u. a. mit einer Stelle aus Alanus' ,Anticlaudianus' (zu v. 4f.). - Zur ,Goldenen Bulle', ihren Entstehungskontexten und ihrer Wirkung zuletzt Ulrike Hohensee / Mathias Lawo / Michael Lindner et al. (Hrsg.), Die Goldene Bulle. Politik - Wahrnehmung - Rezeption, 2 Bde. (Berlin-Brandenburgische Akademie der Wissenschaften. Berichte und Abhandlungen, Sonderband 12.) Berlin 2009. tisch ist, im Sprachrohr der Natura an sich selbst wendet, gleichsam ein über den Intertext von ,De planctu Naturae v vorgetragenes Selbstgespräch oder Soliloquium führt.

Mit einer Bekräftigung (,Confirmatio', Z. 78-87) und anschließenden Entgegnung (,Confutatio', Z. 88-91) untermauert Natura ihre Argumentation. ${ }^{50}$ Auch dieser Abschnitt enthält intertextuelle Signale; mit ihrem anaphorischen $v b i$ verweisen die Fragesätze auf die der mittelalterlichen Memento-mori-Literatur und Todesdidaktik entstammende Ubi-sunt-Topik (Ubi sunt qui ante nos in mundo fuere?, „Wo sind sie nun, die vor uns auf der Welt waren?" $)^{51}$ Interessanterweise wird der im Tod zerronnene Glanz früherer Zeiten hier nun aber nicht, wie man angesichts der vorausgehenden Ausführungen erwarten würde, auf die Wissenschaft, sondern auf die Dichtkunst bezogen: Genannt werden einschlägige Repräsentanten wie die Quellen des Parnass und des Helikon, die Leier des Orpheus, die Musen und andere mehr. In einer abschließenden Entgegnung vollzieht Natura eine - wohlgemerkt immer noch an den Verfasser des Briefs gerichtete - Drohgebärde: „Doch genügen möge Dir, was hier mit schrecklichem Brüllen gesagt und wie in einer Satire vermengt worden ist" (Sufficiant hec tibi ad rugitum dicta satirica, Z. 88): ${ }^{52}$ Der von den weltlichen Wissenschaften und der Dichtkunst begeisterte Bischof möge künftig die „heilbringenderen Ratschläge [s]eines Kaisers" beherzigen (tui Cesaris amplectere consilia saniora, Z. 90f.).

Die abschließende Conclusio (Z. 91-95) führt die Entgegnung fort, indem sie das Eingangszitat aus dem Hebräerbrief aufgreift und dabei betont, dass die wissenschafts-

50 Vom Verfahren her erinnert dieser Abschnitt an die in einzelnen, Artes dictandi` erwähnten Briefteile der ,Confirmatio' und ,Confutatio', welche die Bekräftigung der eigenen Position (hier Z. 78 87) und die Zurückweisung der Argumentation des Gegners (hier Z. 88-91) beinhalten. Vgl. zur "Confirmatio“ als nostre partis cum quadam asseuerantia frequens assertio und zur ,Confutatio" als infirmatio uel reprehensio argumentationum partis aduerse z. B. die in den 1270er Jahren von einem Pariser Verfasser angefertigte ,Ars dictandi', welche unter dem Namen des magister Iohannes anglicus überliefert ist; Rockinger, Briefsteller und formelbücher (wie Anm. 37), 483-512, hier Kap. VIII, 496.

51 Vgl. Clarl] H[einrich] Becker, Ubi sunt qui ante nos in mundo fuere, in: Aufsätze zur Kultur- und Sprachgeschichte vornehmlich des Orients. Ernst Kuhn zum 70. Geburtstage am 7. Februar 1916 gewidmet von Freunden und Schülern. Breslau 1916, 87-105; Etienne Gilson, Tables pour l'histoire du thème littéraire Ubi sunt?, in: Ders., Les Idées et les lettres. Paris 1932, 31-38; Mary Ellen Becker, The Ubi sunt. Form, theme and tradition. Diss. phil. Tempe, Ariz. 1981; Christian Kiening, Contemptus Mundi in Vers und Bild am Ende des Mittelalters, in: Zeitschrift für deutsches Altertum und deutsche Literatur 123, 1994, S. 409-457, hier 412, mit weiterer Literatur.

52 Den Ausdruck satirica verstehe ich im Sinne von satura / satira (ursprünglich eine mit Früchten gefüllte Schüssel, dann: ,Allerlei', ,Gemengsel', ,Vermischtes', ferner: ,Sammlung von Stegreifgedichten', auch: ,Prosastück', ,didaktisches Gedicht'). Vgl. z. B. B[ernd] A[uerochs], Art. Satire, in: Metzler Lexikon Literatur. Stuttgart/ Weimar, ${ }^{3}$ 2007, 677-679. Möglicherweise spielt der Verfasser mit dem Begriff auf die ,Vermengung' von Quellenbeständen (wie Bibelzitaten und Alanus' ,De planctu Naturae') in seinem Text an. Der Bezug auf die literarische ,Satire im neuzeitlichen Verständnis, so Hergemöller, Cogor adversum te (wie Anm. 5), 84, scheint mir jedenfalls nicht zwingend gegeben; Huber, Aufnahme und Verarbeitung (wie Anm. 40), 261, übersetzt mit ,Strafrede`. 
freundliche Haltung des Bischofs nunmehr argumentativ außer Kraft gesetzt sei: „denn lebendig ist die Rede ${ }^{53}$, mit der er dich widerlegt hat; wahrhaftig und unwiderlegbar ist seine Beweisführung" (,vivus est sermo" quo te redarguit; verax est eius et reprehensione carens probacio, Z. 91, vgl. zum Zitat Z. 1); der Bischof wird ermahnt, künftig den Rat des Kaisers zu beherzigen. In den Schlussworten des Briefs vermischen sich hier mithin die Reden der immer noch in Personifikation sprechenden Natura und des Kaisers. Es scheint auf eine Auseinandersetzung zwischen dem Kaiser und dem Bischof angespielt, deren Fokus außerhalb der im Brief dargelegten Argumentation liegt. Hier zeichnet sich ein Konflikt ab, der sich in der außertextlichen Realität abgespielt haben mag. In der Tat deuten weitere von Johann von Neumarkt unterzeichnete Briefe darauf hin, dass sein Verhältnis zum Kaiser von Spannungen geprägt und besonders in den letzten Lebensjahren getrübt war. ${ }^{54}$

Umso auffälliger sind die dem Brief eingeschriebenen Hybridisierungsvorgänge: Die Rede der Natura verweist auf die Rede des Kaisers, dessen biblisch legitimierter sermo vivus zugleich mit der Autorität der Rede Gottes, ja des göttlichen Logos auftritt. Dieser Überblendungsstrategie dienen intertextuelle Bezugsetzungen mittels wörtlichen und indirekten Zitaten (u. a. aus dem Hebräerbrief, Alanus' ,De planctu Naturae' und dem ,Carmen Paschale' des Sedulius). Hierzu gehören auch das erwähnte, zwischen Kaiser und Gott changierende Attribut inuictus (Z. 1, 18, 75) sowie der abschließende Hinweis auf das Ergründen der Schrift (scriptura, Z. 93), welches von der Rinde bis ins Mark vordringe (ad medullam, Z. 95). Bei dieser in der mittelalterlichen Bibelexegese gängigen Bildlichkeit ${ }^{55}$ bleibt definitiv offen, ob sie auf die in Schrift geronnene Rede des Kaisers oder auf Gottes , heilige Schrift' zu beziehen ist. Zugleich eignet der Aussage ein selbst-

53 Nach Hebräer 4,12 (vgl. oben, 277).

54 Vgl. Briefe Johanns von Neumarkt. Ed. Piur (wie Anm. 24), Nr. 31 (Aliquando reputatus, nunc autem contemptus cancellarius vester, 55); Nr. 37 (im Kommentar der Hinweis auf eine „,mehrmonatige Trennung des Kaisers vom Kanzler (...), die bei diesem das Gefühl der Zurücksetzung oder 38-44 (Kontext zur Entlassung aus den Kanzleramt, 68-75); ferner Clifion-Everest, Johann von Neumarkt (wie Anm. 8), 41f. - Den Brie deshalb auf die späten Jahre des Bischofs zu datieren, wie Piur in der Ausgabe vorschlägt („,13761378?“, ebd., 79) ist gleichwohl nicht zwingend, da er eine grundlegende geistige Spannung in der Hofgesellschaft zum Ausdruck bringen kann. Wie unten, 283f., zu zeigen sein wird, passt der Brief gut zu Texten im Prager Umkreis, die ihrerseits um 1355 entstanden sein dürften.

55 Die medulla-Metapher bezeichnet traditionell den tieferen geistigen Sinn sprachlicher Äußerungen, besonders in der Bibel, so z. B. bei Hugo von St. Victor, Allegoriae in Novum Testamentum, in: Hugonis de S. Victore (...) Opera Omnia, Bd. 1. Ed. Jacques-Paul Migne. (Patrologiae cursus completus. Series Latina, Bd. 175.) Turnhout 1854, 749-924, hier 758D: medulla spiritualis intelligentiae. In diesem Horizont auch das abwertende Urteil über einige Grammatiker am End des Grammatik-Abschnitts in Alanus' ,Anticlaudianus': Alain de Lille, Anticlaudianus. Ed. R[obert] Bossuat. (Textes philosophiques du Moyen Age, Bd. 1.). Paris 1955, 87, II, vv. 509511: scriptura (...) minime dignata fateri / Gramaticos humiles, qui sola cortice gaudent, / Quos non dimittit intus pinguedo medulle. reflexiver Zug, denn letztlich ist es ja der Verfasser, der mit seinem Brief das als Rede der Natura bzw. des Kaisers bzw. Gottes ausgewiesene Schriftstück vorgelegt hat

Die Konvergenz göttlichen und natürlichen Wirkens in der Legitimierung des Kaiseramtes lässt sich im Übrigen an den herrschaftspolitischen Diskurs der Zeit anbinden. Staatstheoretiker wie Dante oder William Ockham werden nicht müde zu betonen, dass sich die Herrschaft von göttlichem und natürlichem Recht herleite, wenn sie den kaiserlichen gegenüber dem päpstlichen Machtanspruch zu legitimieren suchen ${ }^{56}$ Ähnlich heißt es in Heinrichs von Mügeln volkssprachiger Dichtung ,Der meide kranz' (kurz nach 1355), dass Karls IV. Regentschaft durch got und Nature begründet werde. ${ }^{57}$ Hier ist also jene Art der Rechtfertigung zu greifen, die Karl dazu verhilft, seinen universalen Machtanspruch auch gegenüber dem Papst zu behaupten. Dieser Anspruch ist für den Kaiser freilich ohne das offene Bekenntnis zum christlichen Glauben und zum Primat der Theologie nicht zu haben. Entsprechend konsequent vertritt Karl den Vorrang der Theologie in der zeitgenössischen Wissensordnung. Ein Reflex dieser Haltung findet sich wiederum in Mügelns ,Der meide kranz', wo Karl IV. einen Wettstreit der Wissenschaften zugunsten der Theologie entscheidet - dies gegen das Plädoyer des in der allegorischen Handlung auftretenden Dichters, der zunächst für die Philosophie votiert, sich dann aber der Entscheidung des Kaisers fügt. ${ }^{58} \mathrm{Zu}$ erinnern wäre auch an das aus dem Umfeld der Prager

56 Vgl. zu den staatsrechtlichen Positionen bis ca. 1350 die Quellen und Darstellungen bei Jürgen Miethke / Arnold Bühler, Kaiser und Papst im Konflikt. Zum Verhältnis von Staat und Kirche im späten Mittelalter. (Historisches Seminar, Bd. 8.) Düsseldorf 1988; ferner Huber, Karl IV. (wie Anm. 35), 78-85, und Schlotheuber, Autobiographie Karls IV. (wie Anm. 31), 588. Zu den politischen Schriften stellvertretend (mit ausführlicher Einleitung und Kommentar): Dante Alighieri, Monarchia. Ed. Ruedi Imbach / Christoph Flüeler. Stuttgart 1989; Wilhelm von Ockham, Texte zur politischen Theorie. Exzerpte aus dem Dialogus. Ed. Jürgen Miethke. Stuttgart 1995. Eine Abschrift von Dantes ,Monarchia' wurde vermutlich von Cola di Rienzo während dessen Aufenthalt in Böhmen (um 1350) fertig gestellt. Vgl. Bartoš, Dantova ,Monarchie‘ (wie Anm. 8); Zdeněk Kalista, Dell'Istituto universitario orientale. Sezione Shya, 1963, 85-117, Pier Giorgio Ricci, Il commento di Cola di Rienzo alla ,Monarchia ' di Dante, in: Studi Medievali, ser. 3, 6.2, 1965, 665-708; sowie Dante, Monarchia. Ed. Imbach / Flüeler (wie oben), $357 f$.

57 Die kleineren Dichtungen Heinrichs von Mügeln. Zweite Abteilung. Ed. Karl Stackmann. Mit Beiträgen von Michael Stolz. (Deutsche Texte des Mittelalters, Bd. 84.) Berlin 2003, 48-203, hier 97, v. 758 (ähnlich bereits 55, v. 113). Dazu Huber, Karl IV. (wie Anm. 35), 66-68; Volfing, Heinrich von Mügeln (wie Anm. 35), 43. Zur Darstellung Karls IV. in der zeitgenössischen Literatur zuletzt Schubert, Inszenierung und Repräsentation (wie Anm. 9).

58 Kleinere Dichtungen. Ed. Stackmann (wie Anm. 57), 48-203, hier 99, vv. 781-784: der ersten [Philosophie] wold er geben den sig, / da winkt im sines herzen blick, / das wird und er und lobes art / der letzten [Theologie] von dem keiser wart. Zur Stelle zuletzt mit divergierenden Deutungen Volfing, Heinrich von Mügeln (wie Anm. 35), 193-195; Stolz, Artes-liberales-Zyklen (wie Anm. 2), 573; Karl Stackmann, ,Der meide kranz . Das nuwe ticht Heinrichs von Mügeln, in: Zeitschrift für deutsches Altertum und deutsche Literatur 135, 2006, 217-239, 222f.; Michael Stolz, ,Vernunst ${ }^{\star}$ Funktionen des Rationalen im Werk Heinrichs von Mügeln, in: Klaus Ridder / Eckart Conrad Lutz / 
Hofgesellschaft stammende Dialoggedicht, Cogor adversum te' (um 1356?), in welchem ein Mensch (homo) gegenüber der personifizierten Welt (mundus) erfolgreich die Auffassung vertritt, dass ein religiöses, auf Gott ausgerichtetes Leben gegenüber diesseitigen Interessen und weltlicher Daseinsfreude vorzuziehen sei. ${ }^{59}$

Vergleichbaren Haltungen ist der vorliegende Brief verpflichtet. Hier wie dort wird der intellektuelle Anspruch einer Bevorzugung der weltlichen Wissenschaft und der Literatur zugunsten der Theologie zurückgedrängt. Auffällig ist, dass sich die erwart bare Mentalität von Kleriker- und Laienstand dabei regelrecht umkehrt: Die klerikalen bzw. klerikal gebildeten Vertreter der Hofgesellschaft, wie der Verfasser von Brief 48 (Johann von Neumarkt?) und Heinrich von Mügeln, plädieren für die weltliche Wissenschaft, während sich der - seinerseits hoch gebildete - Fürst für den Glauben und die Theologie entscheidet.

Die Zustimmung zum kaiserlichen Standpunkt scheint in den Kreisen der Prager Hofgelehrten - wie die Texte erahnen lassen - nur widerstrebend erfolgt zu sein. Im komplexen Verschnitt der Reden Gottes, der Natura und des Kaisers wendet sich der von einem Hofkleriker verfasste Brief 48 zwar gegen die weltlichen Wissenschaften und die Dichtkunst. In seiner Machart aber gibt er zugleich ein Schaustück literarischer Kunstfertigkeit ab: Der sprachliche Stil ist rhetorisch geschliffen, was insbesondere für die von Alanus übernommene Rede der Natura gilt. Kunstvolle Lautresponsionen, sprachliche und gedankliche Kontrastfiguren, effektvoll gebaute Satzgefüge wechseln einander ab Der Schluss des aus ,De planctu Naturae' zitierten Abschnitts enthält zudem eine der für Alanus typischen Metaphorisierungen, deren Bildspender dem sprachlichen Bereich entstammt: Die graduelle Unterschiedenheit göttlicher, natürlicher und menschlicher Macht wird in den Begriffen sprachlicher Steigerungsformen verdeutlicht: dem Superlativ, Komparativ und Positiv. ${ }^{60}$ Dass der Briefschreiber ausgerechnet den Text des in

Susanne Köbele (Hrsg.), Reflexion und Inszenierung von Rationalität in der mittelalterlichen Literatur. Blaubeurer Kolloquium 2006. (Wolfram-Studien, Bd. 20.) Berlin 2008, 205-228, hier $219 f$.

59 Überliefert in drei Handschriften, die auch die ,Maiestas Carolina' bzw. die ,Vita Caroli Quarti` enthalten. Vgl. Hergemöller, Cogor adversum te (wie Anm. 5), 1f. (zur Überlieferung), 3-45 (Edition und Übersetzung), 45-125 (Textanalyse). Hergemöller schätzt Brief 48 „fast wie eine Prosafassung des Cogor-Dialoges" ein (82). Durch minutiöse Textvergleiche kommt er zum Schluss, dass „der gesamte Cogor-Text als Produkt der Prager Kanzlei Karls IV. betrachtet werden muss und höchstwahrscheinlich von Johann von Neumarkt und seinem Mitarbeiterkreis verfasst wurde" (84f). Formal und inhaltlich lassen sich ferner Bezüge zwischen der lateinischen se und dem deutschen Streitgedicht ,Ackermann" des Johannes vo Tepl erkennen (vgl. ebd., 87-120), so dass Hergemöller letzteres ,als Ergebnis eines langsam gewachsenen, heterogenen, durch äußere Struktur des Prager Hofes (...) verbundenen Wirkungszusammenhangs" deuten kann (119). Hergemöllers Forschungsergebnisse werden auch kurz referiert bei Nechutová, Lateinische Literatur (wie Anm. 8), 182.

60 Et sic in quodam comparacionis triclinio tres potestatis gradus possumus inuenire, vt videlicet De potencia superlatiua, Nature vero comparatiua, hominis autem potencia positiua dicatur (Z. 59-62) Zu Alanus' Vorliebe für Bildspender aus dem Bereich der Grammatik (besonders auch für Bildempfänger im Bereich des Sexuellen) Jan Ziolkowski, Alan of Lille's Grammar of Sex. The Meaning of
Prager Hofkreisen ob seiner literarischen Artifizialität und wissenschaftlichen Versierthei beliebten Alanus ab Insulis bemüht, um sein Plädoyer für die Theologie vorzutragen, irritiert. Wie Jan Huizinga gezeigt hat, ist es ja gerade die „Verknüpfung des Poetischen mit dem Theologischen“", welche die Dichtkunst des Alanus auszeichnet. ${ }^{61}$ In ,De planctu Naturae', so lässt sich sagen, überwiegt zweifellos das Poetische, da der gesamte Text als Inszenierung einer Vision angelegt ist, in welcher der Dichter mit der personifizierten Natura in diskursive Interaktion tritt - von dem anstößigen Rahmenthema, der von Natura beklagten Homosexualität einmal ganz abgesehen. ${ }^{62}$ Der Brief stellt in dieser Bezugnahme auf den in der Prager Hofgesellschaft beliebten Dichter Alanus ab Insulis ${ }^{63}$ geradezu einen performativen Selbstwiderspruch aus.

Im Hinblick auf eine an Methoden der angelsächsischen ,Intellectual History ' orientierten kommunikationstheoretisch geleiteten Neuausrichtung von Geistesgeschichte erweist sich der betrachtete Text und mit ihm die geistige Situation Prags im 14. Jahrhundert als ergiebiger Objektbereich. Der Brief gestaltet den intellektuellen Widerstreit zwischen weltlicher Literatur und Wissenschaft einerseits, Theologie und Glauben andererseits als komplex gebautes Sprachspiel, zu dem intratextuelle Responsionen und intertextuelle Bezugnahmen ebenso gehören wie mehrschichtig angelegte Sprechwei-

Grammar to a Twelfth-Century Intellectual. (Speculum anniversary monographs, Bd. 10.) Cambridge, Mass. 1985; zur Stelle und zu weiteren metaphorischen Verwendungen der grammatischen Steigerungsformen ebd., 31; ferner Hergemöller, Cogor adversum te (wie Anm. 5), 68f.

61 Vgl. J[an] Huizinga, Über die Verknüpfung des Poetischen mit dem Theologischen bei Alanus ab Insulis, in: Mededeelingen der Koninklijke Akademie van Wetenschappen. Afdeeling letterkunde 74 / B, 1932, 89-199 bzw. 1-111.

62 So tendenziell auch Huizinga: „Von dieser dichterischen Polychromie, die auch in der Prosa des ,De Planctu' waltet, findet man in den theologischen Schriften des Alanus sehr wenig" (Verknüpfung [wie Anm. 61], 31). - „Der Übergang vom theologischen Begriff zum dichterischen Bilde ist in al diesen Fällen kaum zu bestimmen. Wo wird natura zur Person?“ (ebd., 41). - „In der Ausarbeitung seines Themas nun aber führt Alanus eine ganze Reihe von Gestalten ein, die in der theologischen Spekulation keinen Platz haben“ (ebd, 44) - .Er kennt genau den Begriff der poetischen Fiktion" (ebd., 87). - „Die Dichtung des Alanus schwebt in einer Zone des halben Glaubens, zwischen Über(ebd., 87). - „Die Dichtung des Alanus schwebt in einer Zone

63 Piur spricht mehrfach vom „Lieblingsschriftsteller Johanns v. N.“ (vgl. Briefe Johanns von Neu markt. Ed. Piur [wie Anm. 24], 508, ähnlich 79). Verweise in Johanns Briefen auf den Besitz von Alanus-Handschriften, auf Auszüge, Paraphrasen und Anspielungen sind, ausgehend vom Register (ebd., 532) zusammengestellt bei Huber, Aufnahme und Verarbeitung (wie Anm. 40), 396, Anm. 113. Huber verweist mehrfach auf das Desiderat einer Aufarbeitung der Prager Alanus-Rezeption: „Die Auseinandersetzung Heinrichs (sic!) von Neumarkt mit Alanus (...) ist noch zu untersuchen. (...) Sie wird Aufschlüsse über die Wirkung des Alanus im Umkreis des Prager Hofes bringen, an dem sich offenbar auch die deutsche Rezeption des 14. Jahrhunderts zentriert" (ebd., 216); vgl. auch 236f. (mit einer etwas missverständlichen Kurzbeschreibung von Brief 48 in Anm. 129), 304f., 395. Weitere Indizien zur Prager Alanus-Rezeption, u. a. noch zwei Generationen später in der ,Recommendacio arcium liberalium ' des hussitischen Magisters Hieronymus von Prag (um 1370 in Prag geboren, 1416 in Konstanz verbrannt) bei Šmahel, Präger Universität (wie Anm. 35), bes. 397.403. 
sen. Im Hinblick auf den Diskursraum Prag lassen sich zudem Kontextbezüge herstellen, sei es zur Literatur (wie etwa Heinrich von Mügeln oder dem anonymen Dialog ,Cogor adversum te'), zur zeitgenössischen Staatstheorie (wie dem in Prag bekannten Dante und der ,Goldenen Bulle`) oder zur im Städtebild präsenten Architektur und Bildkunst, die den sakralen Herrschaftsanspruch des Kaisers plastisch untermauern Wie durchlässig die Texte und andere symbolische Artefakte dabei auf konkrete biographische oder historische Sachverhalte sind, muss im Einzelnen offen bleiben. Dies zeigt sich etwa daran, dass der vorliegende Brief nicht mit letzter Sicherheit an die Person Johanns von Neumarkt anbindbar ist. Was in den Quellen hingegen greifbar wird, sind diskursiv verhandelte Haltungen und Mentalitäten - vermittelt in der Sprache vormoderner Textualität.

\section{Anhang 1}

Johann von Neumarkt (?), Brief 48, An Karl IV. Abdruck aus: Briefe Johanns von Neumarkt. Ed. Paul Piur. Mit einem Anhang: Ausgewählte Briefe an Johann von Neumarkt, urkundliche und briefliche Zeugnisse zu seinem Leben. (Vom Mittelalter zur Reformation, Bd. 8.) Berlin 1937, 79-83.

48.

AN KARL IV

Die Mahnrede des Kaisers habe ihn beschämt und ihm den Entschluß eingegeben, sich von der Beschäftigung mit weltlicher Wissenschaft und Poesie abzuwenden. Auch die Natura des Alanus ab Insulis rate ihm das gleiche.

$$
\text { [1376-1378?] }
$$

Viuns est sermo tuus, Cesar inuicte. Etenim e beato quodam diuinitatis fonte scaturiens, amenissimi spiritus grato viuidoque rore perfusus, aures dulcorat et lenit, voluntatem dirigit, inflammat affectum, vt in veritate michi tribuat ammiracionis materiam, que te pridem attulerint tam leta secula, quibus felicibus auspiciis 5 eruperit magnifice tue Serenitatis origo, qualis in tuo principio felix illa fuerit et predicanda laude permixtio celestium radiorum.

Nam tui sermonis facuncla pariter et fecunda progressio penetrabilior gladio quouis ancipiti mentem humilis et indigne creature tue

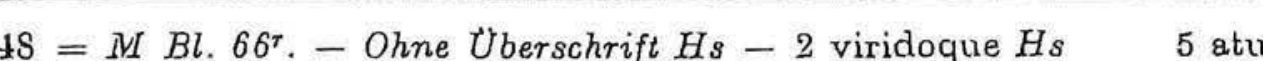
lerint $H s \quad 6$ magnifica $H_{s} \quad 8$ facundia pariter et facunda (so) $H_{s}$

48 Der sich als episcopus (Z. 65) bezeichnende Briefschreiber, der auf den Rat des Kaiser's seinen bisherigen literarischen Neigungen (Parnassus, Helicon, Pegasus usw., Z. ' $79 f f$.) entsagen will, kann kaum ein andrer als Johann v. N. sein. Das lange Zitat aus Alanus von Lille (Z. 23-62), der zu den Lieblingsschriftstellern des Kanzler's gehört (s. die Anm. am Schlu $\beta$ dieses Briefes und unten $N r$. 131. 348), macht clie Vermutung, die durch den Stil nahegelegt wird, nahezu zur Geiwißheit. Für die Datierung gibt das Todesjaht des Kaisers (1378) den äußersten Terniin.

I Viuus sermo: vgl. unten zu Z. 8-11 und oben Nr. 33, 19.

5 Vergil Aen. 1, 605f.:$$
\begin{aligned}
& \text { que te tam laeta tulerunt } \\
& \text { saecula? qui tanti talem genuere parentes? }
\end{aligned}
$$

.8-Il Hebr. 4, 12 Vivus est enim sermo Dei et efficax et penetrabilior omni gladio ancipiti et pertingens usque ad divisionem animae ac spiritus, compagum quoque ac medullarum. 
${ }^{10}$ sic penetrat, vt iam compagem ossium el medullarum attigerit, faciens vtique anime et spiritus gratissimam seccionem. Iam enim floride oracionis tue medicina salubri animum ab erroribus reuocas. Nam philosophia contempta ad eam nunc supernaturalem philosophiam intellectus mei aciem dispono conuertere, que non racionum proba 16 bilium argumentis innititur, non loyca cauillacione distrahitur, non mathematica persuasione fulcitur, sed in eo beatam sibi sedem vendicat, in eo veritatis fundamenta metatur [?], qui lapis ab scisus de monte sine manibus sue virtutis inuicta potencia sustinet vniuersa.

30 Fingo namque naturam rerum assumpta sibi racionabili persona loquentem, vt Alano teste in ueritatis testimonio sui conditoris attestetur potenciam sic dicendo:

'Ego, Natura, summi magistri me profiteor humilem fore discipu lam. Ego enim operans operantis Dei non valeo inherere vestigiis, ${ }_{26}$ sed a longe quasi suspirans operantem respicio. Eius enim opus simplex, meum vero multiplex; eius opus sufficiens, meum vero deficiens; eius opus mirabile, meum vero mutabile. Ille innascibilis, ego nata; ille faciens, ego facta; ille mei operis opifex, ego autem opus opificis; ille operatur ex nichilo, ego mendico opus ex aliquo,

so ille suo operatur in nomine, ego autem operor illius sub nomine, ille solo nutu esse iubet existere, mea vero operacio operacionis est nota diuine. Et $\langle v t\rangle$ respectu diuine potencie meam potenciam im-

10 compago $H s \quad$ medularum $H s \quad 12$ reuocans $H s \quad 13$ philosophiam] phisicam $H s$ 14f. probabilis $H_{s} \quad 15$ f. loyca a cauill. $H_{s}$ 17 metitur $H s \quad 20$ asumpta $H s \quad 21$ Alano teste: im liber de planctu naturae. Die zitierten Sätze sind oben durch Kursivdruck kennt. lich gemacht, stärkere Abweichungen gegenüber dem Text bei Migne (Patr. Lat. tom. $210 \mathrm{col}$. 445f.) im folgenden vermerkt 24 ing (Patr. presse inherere Migne 25 quasi Migne, que Hs opus] operatio Migne 26 vero] opus Migne 30 numine $H s$, nomine Migne

31f. solo nutu esse] rem solo nutu Migne 32f. impotentem Migne

17 Daniel 2, 34 Videbas ita, donec abscissus est lapis de monte sine manibus et percussit statuam in pedibus eius ferreis et fictilibus et comminut ins 2 , 5 Sectndum quod vidisti, quod do monte abscissus est lapis est somnium et fidelis interpretatio eius (Traum des Nabuchodonosor). potenciam esse cognoscas, meum effectum scias esse defectum, meum vigorem vilitatem fore perpendas, auctoritatem theoloyce facultatis consule, cuius. fidelitati pocius quam mearum racionum firmitati a dare debeas assensum. Nam iuxta fidele ipsius testimonium homo mea auctoritate nascitur, Dei auctoritate renascitur. Per me homo a non esse vocatur ad esse, per ipsum vero ab hoc esse in melius perducitur esse. Per me quidem procreatur homo ad mortem, per ipsum autem creatur ad vitam. Sed ab huiusmodi secunde natiuitatis misterio mee professionis ministerium relegatur, nec talis natiuitas tali indiget obstetrice; sed pocius ego, Natura, huius natiuitatis naturam ignoro, et ad hec intelligenda mei intellectus hebet acumen, mee racionis lumen confunditur: intelligencia non intellecta miratur, in insensibilibus sensus obtunditur.

Et cum in hiis omnibus naturalis racio langueat, sola tamen fidei firmitate Dei reuelatur archanum. Nec mirum, si in hiis Theologia suam michi familiaritatem non exhibet, quoniam implerisque non aduersa sed diuersa sentimus. Ego enim racione fidem, illa autem fide comparat racionem; ego scio vt credam, illa credit $v t$ to sciat; ego consencio senciens, illa sentit consenciens; ego vix visibilia video, illa inuisibilia comprehendit in speculo; ego vix minima mecior intellectu, illa immensa racione metitur; ego quasi bestialiter in terra deambulo, illa celi militat in secreto.

Et cum de talibus tractare mei non sit naturalis officii, tamen ad 8 hec sermonem euagari permisi, vt respectu superlatiue Dei potencie meam deminutam esse potenciam non ignores. Sed quamuis meu effectus diuine potencie comparatus deficiat, tamen humane potencie proficit coequatus. Et sic in quodam comparacionis triclinio tres potestatis gradus possumus inuenire, vt videlicet Dei potencia super- в latiua, Nature vero comparatiua, hominis autem potencia positiua dicatur.

36 debes Migne asensum $\mathrm{Hs} \quad 37$ 1. auctoritate] actione Migne 40 autem creatur] recreatur Migne 42 obstitrice $H s \quad 43$ hebet] hēt Hs, habet Migne 44 non intellecta miratur] vero intellecta mutatur Migne 45 in fehlt Migne 46 kein Absatz $B s$ naturalis Migne, naturaliter $4 s$ in 47 rouelatur] vener Migne 51 consencio sciens Migne 52 inuisibila ] in Migne 55 tallibus] praedictis Migne naturalis fech Migne 57 deminutam] divinitatem $\mathrm{Hs}$ ignores] dubites Migne 61 vero] non $\mathrm{H} s$

Burda oh, Mittelalt, a. Reforn. VIII. 
Ad huius ergo demonstratiue argumentacionis seriem, que de naturalis officii deliberacione clarissima auribus tuis ingeritur o6 suscitare ab ignorancie nebulis, imprudens Episcope, assumpti laboris contempnas ineptias, a squalenti sterilitate declinans oculos tui intellectus ad amena paradisi florencia semper nemora ymaginacione beata conuerte! Astrorum loca, cursus et numeros cum suo Ptolomeo, Esculapio vel Hermete relinquas Egipciis, et imperatoris 70 eterni, domini Dei pro te crucifixi, comitare vestigia eiusque graciosa vexilla prosequere, qui te regeneracionis mistice et spiritualis sacri lauacri custodem instituit, te ad presulatus insignia benigne sue gracie muneribus offerendo! Attende que tibi verecundia nuper emerserit, quo rubore tua facies sit ignominiose perfusa, 76 vt inuictissimus Cesar, mundi monarcha, cuius animus rei publice cura frequenter imbuitur, fessas manus retrahens a prosecucione magnalium te nunc instruccione [?] sacra docuerit, cui tu instructor sufficiens esse debueras exemplaris virtutis et morum! Vbi nunc Parnasei latices? vbi nunc rores imbriferi facundi quidem et so disertissima Eliconis? vbi Pegasei fluminis stillicidia graciosa? vbi dulcis Orphei cythara? vbi Amphionis philomene musica similis? vbi nemoris Aonii frondosa densitas? vbi fontis Castalii lauacrum puellare? vbi Syrenum cantus dulcissimi? vbi Pieridum, quas laudabas, amenitas? vbi nunc earum, quibus precipue inseruiueras,

${ }_{85}$ Musarum melliflue cantilene? quem fructum tunc in illis habuisse presumis, de quibus nunc rubore tante verecundie tam viliter erubescis?

Sufficiant hec tibi ad rugitum immanem dicta satirica. Sufficiant tibi, vt merito dolor incensus lacrimarum fontem producat so ex oculis, et huiusmodi vanitate dimissa tui Cesaris amplectere consilia saniora. Nec vacillet [?] opinio, quoniam viuus est sermo quo te redarguit; verax est eius et reprehensione carens probacio. $\begin{array}{cccc}69 \text { hormete } H s & 77 \text { instruccione] intencione } H_{s} & 79 \text { imbriferi] } \\ \text { vmbriferi } H s, v g l . N r .50,11 & 82 \text { Aonii] Enei } H s & 86 \text { presumis } H s\end{array}$ vmbriferi $H s, v g l . N r .50,11 \quad 82$ Aonii] Enei $H s \quad 86$ presumis $H s$
88 ad rugitum immanem: Sinn? 91 Nec vacillet] ne stillet $H s$, auch 88 ad rigitum inmanem: Sinn?

63-95 Der Schlußteil der Rede der Natura ist Zutat des Kanzlers. $63-95$ Der Schlußteil der Rede der Natura ist Zutat des Kanzlers.
82 nemoris Aonii (so auch $\mathrm{Nr} .36,3$ zu ändern): vgl. zu Nr. 344.

82 nemoris Aonii (so auch $\mathrm{Nr}$. 36 ,
Tanto etenim forcius ex eius scriptura proficies quanto eam intimius oculo interiore prospexeris, dum penetratis corticibus perueneris ad medullam'.

\section{5 medullam etc. $H s$}

93 scriptura: der Brief des Kaisers an den Kanzler ist nicht erhalten. 


\section{Anhang 2}

\section{Johann von Neumarkt (?), Brief 48, An Karl IV., Übersetzung ${ }^{1}$}

$<$ Salutatio, Z. 1 Lebendig ist deine Rede ${ }^{2}$, unbesiegbarer Kaiser.

$<$ Exordium 1: benevolum facere, Z. 1-7> Denn sie sprudelt aus einem wahrhaft glückseligen Quell göttlichen Wesens hervor, sie ist durchtränkt vom lieblichen und erquickenden Tau des bezauberndsten Geistes, ist den Ohren süß und lind, lenkt die Gesinnung ihrer Hörer, entflammt Leidenschaft, so dass sie mir fürwahr Anlass zur Bewunderung darüber ist, welch glückliches Zeitalter dich einst hervorgebracht hat ${ }^{3}$, unter welch glücklichen Vorzeichen der Ursprung deiner strahlenden Heiterkei anbrach, welch glückliche und lobenswerte Durchmischung himmlischer Strahlen in deinem Anfang war.

$<$ Exordium 2: attentum facere, Z. 8-12> Der ebenso gewandte wie fruchtbringende Fluss deiner Rede nämlich, schärfer als jedes zweischneidige Schwert, durchdringt ${ }^{4}$ die Gesinnung deines demütigen und unwürdigen Geschöpfes so, dass er nachgerade das Gefüge von Knochen und Mark erschüttert ${ }^{5}$ (hat) ja Seele und Geist ${ }^{6}$ aufs willkommenste zertrennt. Denn allein durch die heilsame Arznei deiner blühenden Rede bringst du den Verstand von seinen Irrtümern ab.

$<$ Exordium 3: docilem facere, Z. 12-19> In Verachtung der Philosophie beabsichtige ich nämlich, die Schärfe meiner Erkenntniskraft nunmehr jener übernatürlichen Philosophie (METAPHYSIK ${ }^{7}$ ) zuzuwenden, die sich nicht auf die Beweismittel glaubwürdiger Vernunftgründe stützt, sich nicht in logischer Wortklauberei verliert, sich nicht auf mathematische Suggestion versteift, sondern die für sich ihren gesegneten Sitz bei dem behauptet und die Fundamente ihrer Wahrheit nach dem ausmisst, der, ein vom Berge ohne menschliches Zutun gelöster Stein ${ }^{8}$, die unbesiegbare Allmacht seiner Kraft in Händen hält.

$<$ Narratio, Z. 20-62> Ich ersinne also eine Rede der Natura rerum, so als hätte sie die Gestalt einer vernunftbegabten Person angenommen, damit sie durch die Zeugenschaft des Alanus im Zeugnis der Wahrheit die Macht ihres Schöpfers mit folgenden Worten bezeuge:

Ich, Natura, bekenne, die demütige Schülerin des höchsten Lehrmeisters zu sein. Ich nämlich vermag es als Wirkende des wirkendes Gottes nicht, mich an seine Spuren zu heften, vielmehr betrachte ich ihn aus der Ferne, einer Seufzenden gleich, in seinem Wirken. Sein Werk nämlich ist einfach, meines aber vielfältig; sein Werk hinreichend, meines aber unzureichend; sein Werk wunderbar, meines aber wandelbar. Er ist selbst ohne Geburt, ich aber bin geboren; er schafft, ich bin geschaffen; er ist meines Werkes Wirker, ich aber bin das Werk des Wirkers; er wirkt aus dem Nichts, ich aber heische mein Werk von einem anderen; er wirkt in seinem Namen, ich aber wirke unter seinem Namen; er bestimmt nur aus seinem Willen heraus alles, was ist, zum Sein, mein Wirken aber ist Zeichen des göttlichen Wirkens. Siehe, meine Macht ist im Vergleich zur göttlichen Macht Ohnmacht; wisse, meine

Für Hilfen bei der Übersetzung danke ich meiner Berner Kollegin Gerlinde Huber-Rebenich.

2 Nach Hebräer 4,12.

3 Nach Vergil, Aeneis I, V. $605 \mathrm{f}$

4 Nach Hebräer 4,12.

5 Nach Hebräer 4,12.

6 Nach Hebräer 4,12.

7 Handschrift: supernaturalem phisicam; dagegen Piur: supernaturalem philosophiam.

8 Nach Daniel 2,34 und 2,45.
Wirkkraft ist wirkungslos; erwäge selbst, wie nichtig mein Vermögen sein wird; suche Rat bei der Geltungskraft theologischer Lehre, deren Verlässlichkeit im Glauben du eher beistimmen solltest als der Festigkeit meiner Vernunftregeln. Denn wie ihr glaubwïrdiges Zeugnis bekundet, wird der Mensch auf mein Geheiß hin geboren, auf Gottes Geheiß hin aber wiedergeboren. Durch mich wird der Mensch vom Nichtsein ins Sein gerufen, durch ihn aber von diesem Sein in ein besseres geleitet. Durch mich wird der Mensch nur zum Tode gezeugt, durch ihn aber wird er zum Leben erschaffen. Durch das Geheimnis einer solchen zweiten Geburt wird die Ausübung meines Tuns zunichte, denn eine solche Geburt bedarf keiner Hebamme wie ich es bin. Fürwahr, ich Natura, mache mir keinen Begriff von der Natur dieser Geburt; dies zu verstehen, ist die Schärfe meiner Verstandes zu stumpf, meiner Vernunft Licht verunklärt sich: die Einsicht bestaunt das Unverstandene, der Sinn versagt vor dem, was ihm nicht zugänglich ist.

Da bei all den Geheimnissen der zweiten Geburt die natürliche Vernunft erlahmt, enthüllt sich das Mysterium Gottes doch nur durch die Festigkeit des Glaubens. Kein Wunder, dass sich dabei die Theologie nicht als mir vertraut erweist, da wir in vielerlei Hinsicht wenn nicht in gegensätzliche, so doch in unterschiedliche Richtungen gehen. Ich nämlich bereite den Weg des Glaubens mittels der Vernunft, sie aber den Weg der Vernunft mittels des Glaubens; ich besitze Wissen, um zu glauben, sie glaubt, um zu wissen; ich stimme bei, indem ich erkenne, sie erkennt, indem sie beistimmt; ich sehe kaum, was sichtbar ist, sie aber begreift mit ihrem Spiegel, was unsichtbar ist; ich ermesse mit meiner Erkenntniskraft kaum das Kleinste, sie aber ermisst mit ihrer Vernunft das Unermessliche; ich streife einem Tier gleich durch die Erde, sie aber leistet ihren Dienst in den geheimen Gefilden des Himmels. Und da von solchen Dingen zu handeln nicht meine natürliche Aufgabe ist, erlaubte ich mir doch in meiner Rede dahin abzuschweifen, auf dass du erkennst, wie gering meine Macht im Vergleich mit zu der unübertrefflichen Macht Gottes ist. Doch obwohl meine Wirkkraft verglichen mit der göttlichen Macht wirkungslos ist, hat sie gegenüber der menschlichen Macht einen Vorsprung. Und so können wir gewissermaßen auf dem Dreierbett der Komparation drei Grade der Macht vorfinden, indem nämlich Gottes Macht als superlativ, jene der Natur aber als komparativ, die Macht des Menschen hingegen als positiv bezeichnet wird.

$<$ Petitio, Z. 63-78> Zur Reihe dieser darlegenden Beweisführung also, die dir ausgehend von der klarsten Erwägung über die Aufgabe der Natura zu Gehör gebracht wird, erhebe dich vom Nebelschleier der Unwissenheit, ahnungsloser Bischof, verachte die Untauglichkeit der geleisteten Anstrengung, lenke die Augen deiner Erkenntniskraft ab von verschmutzter Öde, und wende sie in glückseliger Anschauung auf die lieblichen, immergrünen Haine des Paradieses $!^{10}$ Standort, Lauf und Zahl der Gestirne lass' bei ihren Ägyptern Ptolemäus, Äskulap oder Hermes; wandle stattdessen auf den Spuren des ewigen Kaisers, des für dich gekreuzigten Herrgotts, und folge den gnadenreichen Fahnen dessen, der dich zum Wächter der mystischen Wiedergeburt und der heiligen Taufe im Geiste bestellt hat, indem er dich freundlich mit der Gunsterweisung seiner Gnade den Würden des Bischofsamtes darbot! Sieh', welche Ehrfurcht neulich in dir aufstieg, welche Schamröte dein Gesicht schändlich überlief, als der unbesiegbarste Kaiser, Herrscher der Welt, dessen Gesinnung unablässig von der Sorge um das Staatswesen erfüllt ist, deine erschöpften Hände von der Wahrnehmung großer Aufgaben zurückzog und dir in heiliger $A b s i c h t^{11}$ beibrachte, wem du hinlänglicher Lehrer eines Vorbilds an Tugend und Sitten zu sein schuldetest!

9 Nach Alanus ab Insulis, De planctu naturae. Ed. Häring (wie oben, 278, Anm. 41), 829,129830,165 .

10 Ähnlich das ,Carmen Paschale' des Sedulius, Lib. I, v. 53f.: sed amoena uirecta/ Florentum semper nemorum, und das einleitende Gebet der Goldenen Bulle, v. 8f.: per amena virecta / Florentum semper nemorum

11 Vgl. Handschrift: intencione, dagegen Piur: instruccione. 
$<$ Confirmatio, Z. 78-87> Wo sind jetzt die Wasser des Parnass ${ }^{12}$ ? Wo das taubringende Nass des so zungenfertigen und überaus beredten Helikon ${ }^{13}$ ? Wo die gedeihlichen Tropfen des Pegasusstroms? ${ }^{14}$ Wo die zarttönende Leier des Orpheus? Wo die nachtigallengleiche Musik ${ }^{15}$ des Amphion ${ }^{16}$ ? Wo das laubreiche Dickicht des Hains von Böotien ${ }^{17}$ ? Wo das Musenbad der kastalischen Quelle ${ }^{18}$ ? Wo die betörenden Gesänge der Sirenen? Wo der Liebreiz der von dir gelobten Pieriden ${ }^{19}$ ? Wo sind jetzt die honigsüßen Lieder jener Musen, denen du mit Vorliebe ergeben warst? Welchen Nutzen erwartest du honigsüßen Licder jener Mus viel Ehrfurcht schmählich erröten denn von jenen (erhalten zu haben), die dich nun aus Scham vor so viel Ehrfurcht schmahich erroten lassen?

$<$ Confutatio, Z. 88-91> Doch genügen möge Dir, was hier mit schrecklichem Brüllen gesagt und wi in einer Satire vermengt worden ist. Genügen möge Dir, dass der entflammte Schmerz verdientermaRen einen Tränenstrom aus den Augen hervorquillen lässt; so beherzige denn, nachdem du solche Eitelkeit

Eitelkeit tebendig ist die Rede ${ }^{20}$, mit der er dich Conclusio, Z. widerlegt hat; wahrhaftig und unwiderlegbar ist seine Beweissent wirst du aus seiner Schrift erzielen, je tiefer du sie mit dem inneren Auge ergründet hast, bis du einst nachdem du die Schichten der Rinde durchdrungen hast, zum Mark vorgestoßen bist.

\section{Zeichenerklärung}

\section{Kursivdruck: Zitate}

(...): Tilgungen gegenüber dem lateinischen Text.

KAPIT

列 (,Ars dictaminis').

12 Zentrales Gebirge Mittelgriechenlands, in der römischen Mythologie Sitz des Apollo und der Musen, Symbol der Dichtkunst.

Gerire

14 Anspielung auf die den Musen geweihte Quelle Hippokrene, die das Flügelross Pegasus auf dem Gipfel des Helikon durch einen Hufschlag hervorgebracht haben soll.

15 Lat. Text: philomene musica similis („die der Philomena ähnliche Musik“). Vgl. griech.-röm. Mythologie: Philomela / Philomena wird von Tereus, dem Mann ihrer Schwester Prokne vergewaltigt. Zur Geheimhaltung der Tat schneidet ihr Tereus die Zunge heraus, worauf Philomela das Geschehen für ihre Schwester auf einem kohn Itys und setzt ihn Tereus zum Mahl vor. Als der erschlachtet Prokne den gemeinsamen Sohn Itys und setzt ihn Tereus zum Mahl vor. Als der erzürnte Vater die beiden Schwestern verfolgt, verwandeln

Philomela in eine Schwalbe (in röm. Tradition umgekehrt).

6 Griech. Mythol

Landschaft um den Helikon.

17 Landschaft um den Helikon.

18 Castalius, Adjektiv zu Castalia (Musenquelle am Parnass bei Delphi).

20 Nach Hebräer 4,12 (vgl. oben 267)

\section{Inhalt}

Klaus Ridder und Steffen Patzold

Einleitung ......

\section{Eröffnung}

Jeffrey F. Hamburger und Hildegard Elisabeth Keller

Bilder in der Kirche, im Herzen oder gar nirgends? Überlegungen zu

Periodisierungen am Beispiel des Bilderstreits in der Frühen Neuzeit

Nation - Europa - Welt

Michael Borgolte

Über europäische und globale Geschichte des Mittelalters. Historiographie

im Zeichen kognitiver Entgrenzung

Ulrich Müller

Die Archäologie des Mittelalters und der Neuzeit im Gefüge der historischen

Archäologien

\section{Vormoderne - Moderne}

Ewald Frie

,Bedrohte Ordnungen ' zwischen Vormoderne und Moderne.

Überlegungen zu einem Forschungsprojekt

Frank Rexroth

Die scholastische Wissenschaft in den Meistererzählungen der europäischen

Geschichte

Toachim Knape

Textleistung. Eine moderne rhetorische Kategorie, erprobt am Beispiel

nittelalterlicher Chronistik 
Martin Baisch

Alterität und Selbstfremdheit. Zur Kritik eines zentralen

Interpretationsparadigmas in der germanistischen Mediävistik

Claudia Lauer

Liebe übersetzt. Friedrichs von Hausen ,Ich denke underwîlen

(MF 51,33) als (vor-)modernes Rezeptionsphänomen

Religion - Wissen

Andreas Holzem

Die Wissensgesellschaft der Vormoderne. Die Transfer- und

Transformationsdynamik des, religiösen Wissens

Michael Stolz

Vivus est sermo tuus. Religion und Wissen in der Prager Hofkultur

des 14. Jahrhunderts

Burghart Wachinger

Religionsgespräche in Erzählungen des Mittelalters

Europäische Werte und Identitäten

Dietmar Mieth

Menschenwürde - vormoderne Perspektiven am Beispiel zweier

Impulse des Spätmittelalters

Klaus Oschema

Ego Europa - die Zukunft eines Kontinents und der Untergang der Welt

Anhang

Daniela Czink

Orts-, Personen- und Werkregister 


\section{Die Aktualität der Vormoderne}

Epochenentwürfe zwischen Alterität und Kontinuität

Herausgegeben von

Klaus Ridder und Steffen Patzold

Akademie Verlag 